\title{
Posttransplant lymphoproliferative disorder in children after allogeneic hematopoietic stem cell transplantation: a single-center experience and literature review
}

Yulia V. Skvortsova ${ }^{1}$, Dmitrij N. Balashov' ${ }^{1}$ Larisa N. Shelikhova ${ }^{1}$, Elena V. Skorobogatova ${ }^{2}$, Yurij A. Krivolapov ${ }^{3}$, Irina P. Shipitsina ${ }^{1}$, Elena I. Gutovskaya ${ }^{1}$, Dina D. Bajdildina ${ }^{1}$, Irina I. Kalinina ${ }^{1}$, Ulyana N. Petrova ${ }^{1}$, Andrej B. Abrosimov ${ }^{1}$, Svetlana N. Kozlovskaya ${ }^{1}$, Michael A. Maschan ${ }^{1}$, Dmitrij M. Konovalov', Dmitrij S. Abramov' ${ }^{1}$, Galina V. Tereshenko', Alexander G. Rumyantsev ${ }^{1}$, Elena V. Samochatova ${ }^{1}$, Galina A. Novichkova ${ }^{1}$, Alexej A. Maschan ${ }^{1}$

${ }^{1}$ National Scientific and Practical Center of Pediatric Hematology, Oncology and Immunology named after Dmitry Rogachev; Ministry of Healthcare of Russia, 1, Samory Mashela Str., Moscow, 117997, Russia

${ }^{2}$ Russian Children Clinical Hospital ; Ministry of Healthcare of Russia, 117, Leninskiy Prospect, Moscow, 119571, Russia

${ }^{3}$ State Institution «Leningradskoye Regional Bureau of Pathological Anatomy», St. Petersburg, Russia

Dr. Yulia V. Skvortsova, PhD, Senior Research Associate, Department for Hematopoietic Stem Cell Transplantation No.2, D. Rogachev Memorial National Scientific and Practical Center of Pediatric Hematology, Oncology and Immunology, 1, Samora Mashel St, Moscow, 117997, Russia

\section{Summary}

Posttransplant lymphoproliferative disorder (PTLD) is one of the most serious complications of allogeneic hematopoietic stem cell transplantation (HSCT). Pathogenesis of this disease is associated with uncontrolled lymphoid tissue proliferation in immunocompromised recipients, most often triggered by primary Epstein-Barr virus infection, or its reactivation. This complication could be fatal, depending on the type of PTLD. This article describes clinical and morphological classification,
Phone: +7 (915) 0693743

E-mail:yuscvo@mail.ru

\section{Introduction}

The number of allogeneic hematopoietic stem cell transplantations (HSCT) continues to increase, including transplants from alternative donors. Therefore, an uncommon HSCT complication called a posttransplant lymphoproliferative disease (PTLD) should be in focus, due to its extreme danger to patients.

risk factors, clinical features, diagnostic and treatment of PTLD and presents the clinical experience of the diagnostic and treatment of PTLD in patients of HSCT departments of Russian Children's Hospital and National Scientific Center of Children's Hematology, Oncology and Immunology.

\section{Keywords}

Allogeneic hematopoietic stem cell transplantation, posttransplant lymphoproliferative disorder.
Since 60's, lymphoid-derived posttransplant neoplasias were first described in renal transplant patients who received immunosuppressive drugs to prevent graft rejection [45]. PTLD is a common complication in solid organ transplant settings, occuring at a rate of 1 to $20 \%$, being dependent on the graft type [7]. Similarly, PTLD may develop after allo-HSCT presenting many factors predisposing for deficient immune surveillance over proliferating B cells. PLTD incidence following allo-HSCT varies between 0.8 and 1.5\% [2]. Some PTLD 
cases are described after umbilical blood transplantation [18], and allo-HSCT with nonmyeloablative conditioning $[5,52]$.

PTLD comprises a group of disorders ranging from benign polyclonal hyperplasia to malignant clonal proliferation [42, $25,8,30,38]$. PTLD is historically recognized as uncontrolled $B$ cell proliferation caused by Epstein-Barr virus (EBV). However, EBV-negative PTLD are described as well [29].

\section{Classification}

All the posttransplant lymphoid neoplasias were previously called immunoblastic sarcomas until PTLD discretion, as a certain clinical entity. In 1987, Frizzera et al. [17] described some distinct polymorphic changes in patients after renal transplantation, and proposed a classification including a non-specific hyperplasia, polymorphic hyperplasia, and polymorphic lymphoma. In 1988, Nalesnik et al. coined a term polymorphic PTLD for the mentioned disorder [39]. Monomorphic PTLD was also described but it could not be differed from a non-Hodgkin's lymphoma. However, mere morphological findings did not provide complete and reliable prognostic information. Knowles et al. [27] added combined molecular genetics criteria to classical morphological features in order to determine cellular clonality, thus developing a PTLD classification including a polyclonal plasmatic hyperplasia, monoclonal polymorphic B cell hyperplasia, or lymphoma, as well as monoclonal pleiomorphic immunoblastic lymphoma, or multiple myeloma.

By 1997, Society for Hematopathology developed a novel classification which initially pointed to differences between early and late PTLD's [24]. In 2001, The World Health Organization (WHO) published current PTLD classification which is used up to present time: 1) initial disturbance, e.g., reactive lymphoplasmacytic hyperplasia, and a syndrome similar to infectious mononucleosis, 2) polymorphic PTLD; 3) monomorphic PTLD, and, 4) Hodgkin's disease-like PTLD (Table 1) $[26,33]$. In 2008 , this classification was supplemented by additional histological criteria.

Table 1. PTLD categories according to WHO Classification of Tumours [26]

\begin{tabular}{|l|l|l|}
\hline Category & Clonality & Clinical characteristics \\
\hline $\begin{array}{l}\text { Early lesions } \\
\text { A) reactive lymphoplasmocytic } \\
\text { hyperplasia } \\
\text { B) Infectious mononucleosis-like } \\
\text { lesions }\end{array}$ & Polyclonal & $\begin{array}{l}\text { Usually spontaneous regression, or following } \\
\text { reduced immunosuppression therapy }\end{array}$ \\
$\begin{array}{l}\text { Polymorphic PTLD } \\
\text { Monomorphic PTLD }\end{array}$ & Polyclonal in most cases & $\begin{array}{l}\text { Variable response to reduced reduced immu- } \\
\text { nosuppression therapy. }\end{array}$ \\
$\begin{array}{l}\text { Classical Hodgkin's lymphoma and } \\
\text { Hodgkin's lymphoma-like PTLD }\end{array}$ & Monoclonal & $\begin{array}{l}\text { Should be classified according to WHO classi- } \\
\text { fication for non-Hodgkin lymphomas } \\
\text { Similar to Hodgkin's lymphoma }\end{array}$ \\
\hline
\end{tabular}

Notes: WHO, World Health Organization; PTLD, posttransplant lymphoproliferative disease; NHL, non-Hodgkin's lymphomas.

\section{Etiology and Pathogenesis}

Primary EBV infection after transplantation is the main factor of PTLD. I.e., the PTLD risk after EBV infection is shown to be increased 10- to 76-fold [7]. EBV, herpesvirus family member may cause of infectious mononucleosis. Human fluids and secretions, e.g., saliva, are a usual transfection source. Over $90 \%$ of humans develop anti-EBV immunity by the age of 40 years. Following primary infection, a long-lasting viral latency is established. An immunocompetent organism has several control mechanisms against EBV proliferation after primary infection, especially, cytotoxic T cell response, and, to lesser degree, humoral (antibody) immune response; NK cell activity, cytokine regulatory pathways [51,35]. EBV transmission to the HSCT recipients occurs mainly via blood products, however, exact incidence of this transfection is undetermined. In cases of B cell PTLD, B cell proliferation and inhibition of specific immune surveillance are the main causal factors [1]. EBV is known to primarily affect naïve $B$ cells which migrate to germinative centers. Specific EBV proteins are stimulating differentiation of B cells to memory B cells that become the EBV depots. In summary, expression of EBV markers (LMP1, 2A-B), and nuclear proteins (EBNA-1, $2,3 \mathrm{~A}-\mathrm{C}$ ) is accompained by development of the virus latency. These latent gene expression is associated with ongoing EBV infection of B cells, and, accordingly, with different kinds of PTLD [37] (Table 2). Hence, EBV genome in immunocompetent subjects exists as episomes providing latency in mem- 
ory B cells. Under inhibited immunity, the T cell control is also lost, thus causing proliferation of EBV-infected B cells, lymphoid cell hyperplasia, and evolving malignancy [32]. $\mathrm{T}$ cell recovery does not yet occur within 6 months postHSCT, thus predisposing for higher PTLD risk during this time period. [4]. However, an increase in late PTLD cases is observed over last years [50]. As a rule, this trend is associated, with low CD4+ lymphocyte levels as it occurs in HIV-infected patients [20].

Table 2. EBV-associated PTLD and viral programs [37]

\begin{tabular}{|l|l|l|l|}
\hline Latency period & $\begin{array}{l}\text { Expressed EBV-specific } \\
\text { proteins }\end{array}$ & $\begin{array}{l}\text { B lympocyte development } \\
\text { stage }\end{array}$ & PTLD type \\
\hline III (growth) & $\begin{array}{l}\text { EBERI-2, EBNA1-6, LMPI, } \\
\text { LMP2A-B }\end{array}$ & Activated B-lymphoblasts & $\begin{array}{l}\text { Post-transplant diffuse large-cell, B cell } \\
\text { lymphoma; } \\
\text { HIV-associated lymphoma; } \\
\text { Acute infectious mononucleosis }\end{array}$ \\
\hline II («silence») & EBER 1-2, EBNA1, LMPI-2A & B cells in germinative centers & $\begin{array}{l}\text { Post-transplant diffuse large-cell B cell } \\
\text { lymphoma; } \\
\text { Hodgkin's lymphoma }\end{array}$ \\
\hline I & EBER 1-2, EBNA1 & Memory B cells & $\begin{array}{l}\text { Burkitt lymphoma, } \\
\text { Post-transplant plasmoblastic lymphoma }\end{array}$ \\
\hline
\end{tabular}

In early PTLD ( $1^{\text {st }}$ year after HSCT) EBV is found in $>90 \%$ of $B$ cells. With time, a year or later after HSCT, the EBV detectability decreases gradually, reaching an average of $21-32 \%$ of total [16]. Over last years, growing number of EBV-negative PTLD's has been registered: from $10 \%$ in 90 's to $48 \%$ over 2008-2013 [34]. Nevertheless, EBV presence is recommended for every bioptate taken using in situ hybridization since EBV status determines appropriate therapeutic approaches. Cytomegalovirus and human herpesvirus could be also detected in blood and tissues of the patients, being, however, an epiphenomenon rather than a disease trigger. [6, 62].

When transplanting solid organ, the PTLD emerges from recipient cells. Meanwhile, both donor and recipient in allogeneic HSCT, are EBV-seropositive in most cases. Hence, lymphoproliferation after allo-HSCT originates from donor cells because lymphoid system in recipient is often virtually destroyed by conditioning treatment. Even in cases of EBV-seronegativity in donor, PTLD develop, due to infection of donor lymphocytes from EBV-positive recipient.

\section{Risk factors}

In addition to EBV infection, a number of other HSCT-associated risk factors for PTLD are reported, e.g.: HLA-compatible donor (RR 3,8-9); T cell depletion (RR 4-12,7), treatment with CD3 antibodies; usage of antithymocyte globulin (ATG) (RR 3.1-6.4), severe acute GvHD, grade $\geq 2$ (RR 1.96.5); extensive chronic GvHD (risk factor for a late PTLD) $[2,53]$. As reported by Uhlin et al. [59], incidence of the EBV-associated PTLD may increase to $10-20 \%$ upon combination of some known risk factors: HLA mismatch, different EBV serology in donor/recipient pairs; reduced intensity conditioning; acute GvHD; splenectomy before HSCT; mesenchymal stem cell infusions. The EBV viral load in cases of viral reactivation does not play a sufficient role. E.g., PTLD was registered in $50 \%$ of the patients with blood EBV contents of $\geq 4,000$ copies per $\mathrm{mL}$ [60]. Meanwhile, current
European Guidelines recommend weekly quantitative PCR screening for EBV in allo-HSCT recipients for a minimum of 3 months post-HSCT [55].

Despite donor origin of proliferating B cells in most HSCT cases, high prevalence of PTLD is described in pediatric population among patients receiving ATG- or Alemtuzumabcontaining conditioning, due to persistence of recipient B cells in this setting $[9,5]$.

One should not underestimate EBV-negative PTLDs which occur at later terms post-HSCT, showing a more aggressive clinical course [40]. Some authors suggest to consider them as "classic" lymphomas developing in transplanted patients [36]. Interestingly, the results of an international multicentric prospective study (Phase 2) do not consider EBV status a significant factor influencing overall survival and progression terms [57].

\section{Clinical Features}

PTLD manifestations may be quite diverse. Lymphadenopathy, or limited affection of lymphoid tissue are most common. Diffuse lesions similar to fulminant septic syndrome may occur more rarely [19]. The disorder may manifest like an acute respiratory viral infection, sometimes exhibiting functional affection of a distinct organ. Many cases could be complicated by cytomegalovirus infection, or by invasive aspergillosis. In some instances, PTLD proceeds symptomless, being detectable as an occasional finding at autopsy. Any HSCT patient presenting with notable adenopathy, bulky lesions, fever, unexplained pain, weight loss, or organ dysfunction should be examined, e.g., for PTLD [32]. Mortality with PTLD reaches $40-70 \%$ after solid organ transplantation. Early mortality from PTLD pst HSCT comprised 90\% a decade ago. Overall five-year survival has increased to $40-60 \%$ by the present time, due to implementation of adoptive cell therapy [11]. Most lethal outcomes are associated with dis- 
ease progression. Other $40 \%$ of deaths are attributed to infections and therapeutic toxicity. Unfavorable prognosis is associated with older age of the patient, advanced disease stages, bad somatic status, CNS affection, as well as increased LDH levels and hypoalbuminaemia.An International Prognostic Index (IPI) may be used as a predictor in PTLD patients.

\section{Diagnostics}

To assess proper diagnosis, EBV detection in blood by means of PCR technique should be used, along with studies of biopsies taken from affected tissues being performed with combined histology, immunophenotyping, immunohistochemistry, molecular techmiques, e.g., in situ hybridization of early EBV DNA (EBER), and PCR for EBV. The disorder should be clearly proven, since some treatment modes could cause severe complications in the patients.

In some cases, polymorphic PTLDs is difficult to discern from infectious mononucleosis or Hodgkin's disease which may manifest with similar disorders [12]. Cell infiltrate in pathological samples consists of lymphocytes, histiocytes and plasmocytes. The latters comprise transformed B blasts expressing CD20 and CD30, bieng CD15-negative. Monomorphic PTLD comply with histological criteria of lymphoma, mostly, B phenotype (especially, B cell lymphoma, diffuse large cell lymphoma, plasmoblastic lymphoma). However, T cell variants are also described (e.g., hepatolienal T cell lymphoma), and combined-type lymphomas. Hodgkin's lymphoma after HSCT occurs sporadically, with Hodgkin and Reed-Sternberg cells being an obligate component of cellular substrate containing plasmocytes, eosinophils and histiocytes. The marker cells exhibit high CD30 and CD15 expression with absence of CD20 and weak PAX5 expression [58]. In Hodgkin's-like PTLD, they are more aggressively presented, being in most cases associated with unfavorable prognosis $[28,48,46]$. These four categories are sometimes hardly discernable, due to cross-presentation of different cellular subsets. Lesions at different sites may exhibit distinct pathohistological pattern. Therefore, correlation with clinical and visualization data should be used to make the diagnosis more correct.

Clonality studies help to confirm the diagnosis. I.e., monomorphic PTLD usually exhibits clonal immunoglobulins or TCR rearrangements, respectively, in $\mathrm{B}$ and $\mathrm{T}$ cell populations. Due to immune suppression, the B cell PTLDs often express oligoclonal reactive $\mathrm{T}$ cell populations detectable by PCR for distinct $\mathrm{T}$ cell receptors. They could not be considered classical $\mathrm{T}$ cell lymphomas despite their lymphoma pattern revealed by histological criteria. For PTLD staging, they use computer tomography (CT) of chest, abdomen and pelvis minor areas, as well serum LDH determination.

To conduct early monitoring of EBV burden before clinical symptoms of the disorder, quantitative PCR of viral DNA from blood serum is performed. However, it does not substitute requirements for local biopsies to perform adequate diagnostics.

Positron emission tomography with fluorodeoxyglucose (F-FDG-PET/CT) is a golden standard, aiming to assess parameters of lesion and its response to therapy. Extreme importance of $\mathrm{PET} / \mathrm{CT}$ is proven, in order to justify terms of treatment, especially for the patients with incomplete response to therapy [56].

\section{Prophylaxis}

The best way to manage PTLD patients is to minimize potential risk factors. E.g., the PTLD risk is sufficiently increased upon usage of anti-CD3 or ATG preparations for T cell depletion, aiming for GvHD control. Respectively, an option of $\mathrm{B}$ cell depletion should be considered if such approaches cannot be avoided. Testing anti-EBV antibodies in donors is an obligate requirement. A seropositive donor is a risk factor in case of seronegative recipient. Additional leucocyte reduction of RBC preparations is recommended, thus allowing to decrease risk for EBV-positive blood products [47]. CMV infection is considered to be a cofactor of PTLD development following solid organ transplantation. Therefore, CMV status of donor and recipient is also of great significance.

Rapid T cell reconstitution is a favorable factor. E.g., incidence of EBV viremia, and, accordigly, PTLD risk in ATG-treated HSCT patients proved to be suffificiently lower at $\mathrm{T}$ cell levels of $>50 / \mathrm{mcL}$ by $\mathrm{D}+30$ [44].

Rituximab (an anti-CD20 monoclonal antibody) could be used as prophylaxis [61] and preventive treatment of PTLD. E.g., a weekly qPCR EBV monitoring at the City of Hope Clinics (USA) is performed since D+21 after HSCT [33]. In case if EBV levels exceed 1000 copies $/ \mathrm{mL}$, the patient is administered a single Rituximab dose. In case of EBV persistence for 6 other weeks, three Rituximab infusions are preformed in addition.

Acyclovir or Gancyclovir usage was also of some interest. Gancyclovir is active in vitro against EBV, however, it may cause a sufficient myelosuppression [31]. The data on its clinical efficiency in PTLD prevention are controversial.

Early studies of EBV-cytotoxic T cell infusions have shown their efficiency for viral load reduction, and those may be used to prevent and treat PTLD [49, 10, 21].

Certainly, B cell depletion of hematopoietic grafts (by means of Rituximab or CD19+ cell depletion) remains the most effective tool for PTLD prevention.

\section{Treatment}

Special guidelines for PTLD treatment were designed on the basis of WHO classification [26]. Type 1 PTLD, or early polyclonal disturbances, including reactive lymphoplasmocytic hyperplasia or infectious monucleosis-like syndromes, do not usually require any interventions, being self-limited. However, reduction of immunosuppressive therapy (IST) is recommended in such cases. Type 2 of the polyclonal PTLD usually needs immunosuppression reduction with variable clinical response. Type 3 (lymphoma) is a subject to treatment in case of reduced immunosuppression and chemotherapy applied. Type 4 PTLD requires aggressive therapeutic approach. 
Efficiency of reduced immunosuppression in PTLD is described as early as in 1984 [54]. This approach works both in EBV-associated PTLD patients, and in EBV-negative conditions. Absence of clinical response is predicted by $\mathrm{LDH}$ increase $>2.5$-fold over normal values, organ dysfunction, multiple organ failure. However, development or aggravation of acute GvHD could occur due to IST reduction, thus sufficiently worsenig prognosis of the disorder.

Rituximab proved to be an effective preparation in PTLD [3, $41,15]$. It is considered to be a "golden standard" for treatment of CD20+ PTLD including mono- and polymorphic lesions. When transplanting solid organs, full clinical response to Rituximab monotherapy was registered in $53-86 \%$ patients $[41,15]$. EBV positivity is a predictor of clinical response. The authors recommend reduced immunosuppression and Rituximab admonistration for the patients with EBV-positive PTLD, whereas polychemotherapy (PChT) is reserved for EBV negative, or Rituximab-nonresponding cases. CHOP and ProMACE-CytaBOM are used as chemotherapy regimens for PTLD, like as in non-Hodgkin's lymphoma. This treatment mode remains problematic, due to high risk of severe infections and increased mortality levels.

Despite the Rituximab efficiency, this drug is inefficient in a group of the PTLD patients, whereas PChT application is limited by it's adverse reactions.
Efficiency of cytotoxic EBV-specific T cells was studied in PTLD patients, however, without distinct results $[49,23]$. Infusions of native donor lymphocytes may promote restoration of $\mathrm{B}$ cell immunity and increase clinical response rates in PTLD to $60-90 \%$ [4]. However, only $41 \%$ of these patients achieved stable remission. HSCT from EBV-seronegative donors and umbilical blood cells are of limited use in this condition. At the present time, HLA-compatible EBV-specific third-party donor lymphocytes are preferrable, thus suggesting $\mathrm{T}$ cell recognition of tumor cells, due to selective restriction of HLA alleles absent from PTLD cells. [13]. However, generation of EBV-specific cytotoxic lymphocytes needs time and expenses, thus limiting clinical usage of this approach. Some workers attempted to develop rapid cultures of EBV-cytotoxic lymphocytes, but their clinical efficiency is not yet proven. At present, donor banks which contain EBV-specific cytotoxic lymphocytes from third-party are arranged. Possible adverse effects may include systemic inflammatory response and minimal GvHD signs. These symptoms fade away upon administration of corticosteroids and Etanecerpt [43]. Cytokine-blocking therapy, e.g., with antibodies against IL-6, a B cell growth stimulant, is described in a Phase I-II multicentric study, showing $41 \%$ of clinical response in early PTLD $[14,22]$. A concise therapeutic protocol is shown in Fig. 1 [11]. Diverse therapeutic approaches in PTLD are featured in Table 3 [11].
Early lesions, polymorphic PTLD and monomorphic PTLD subtype, diffuse large cell B-cell lymphoma (CD20+)

Monomorphic PTLD, non diffuse large cell lymphoma, nonprimary CNS lymphomas
Lymphomaspecific therapy
Continued

follow-up

response

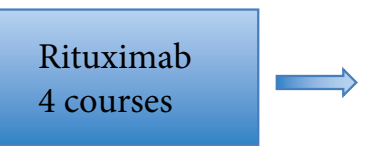

No response
Figure 1. Proposed treatment algorithm for PTLD after HSCT [Dierickx D, Tousseyn T, Gheysens 0 . How I treat posttransplant lymphoproliferative disorders. Blood. 2015 Nov 12;126(20):2274-83. doi: 10.1182/blood-2015-05-615872. Epub 2015 Sep 17. PMID: 26384356]. 
Table 3. Treatment options for PTLD [11].

\begin{tabular}{|c|c|c|c|}
\hline Treatment & $\begin{array}{l}\text { Target cell } \\
\text { populations }\end{array}$ & Benefits & Drawbacks \\
\hline $\begin{array}{l}\text { Immunosuppressive } \\
\text { therapy reduction }\end{array}$ & T cells & $\begin{array}{l}\text { Good response at early stages } \\
\text { of disease. } \\
\text { Preventive therapy. }\end{array}$ & $\begin{array}{l}\text { Time-consuming. } \\
\text { Depends on organ function. } \\
\text { Graft rejection/GvHD risk. }\end{array}$ \\
\hline $\begin{array}{l}\text { Antibodies against } \\
\text { cytokines }\end{array}$ & $\begin{array}{l}\text { T cells } \\
\text { Malignant } \\
\text { B cells }\end{array}$ & $\begin{array}{l}\text { Promising results for efficient } \\
\text { therapy. }\end{array}$ & High toxicity (side effects). \\
\hline Donor lymphocyte infusions & $\begin{array}{l}\text { T cells } \\
(\mathrm{EBV}+)\end{array}$ & $\begin{array}{l}\text { Good response. } \\
\text { Rapidly available. }\end{array}$ & High toxicity (GvHD). \\
\hline $\begin{array}{l}\text { Adoptive immunotherapy } \\
\text { (EBV-specific cytotoxic T } \\
\text { lymphocytes) }\end{array}$ & $\begin{array}{l}\text { T cells } \\
(\text { EBV+) }\end{array}$ & $\begin{array}{l}\text { Promising results in refractory } \\
\text { clinical course. } \\
\text { Low toxicity. } \\
\text { Rapid progress in the field. }\end{array}$ & $\begin{array}{l}\text { Only in EBV+ cases. } \\
\text { Time-consuming. } \\
\text { High costs. } \\
\text { Limited availability. }\end{array}$ \\
\hline $\begin{array}{l}\text { Surgical treatment and } \\
\text { radiation therapy }\end{array}$ & $\begin{array}{l}\text { Malignant } \\
\text { B cells }\end{array}$ & $\begin{array}{l}\text { Rapid amelioration of the } \\
\text { symptoms. }\end{array}$ & $\begin{array}{l}\text { Only for limited lesions (stage 1). } \\
\text { Predominantly palliative treatment. }\end{array}$ \\
\hline Cytostatic chemotherapy & $\begin{array}{l}\text { Malignant } \\
\text { B cells }\end{array}$ & High response level. & $\begin{array}{l}\text { High risk of therapy-associated } \\
\text { morbidity and mortality. }\end{array}$ \\
\hline Rituximab & $\begin{array}{l}\text { Malignant } \\
\text { B cells }\end{array}$ & $\begin{array}{l}\text { Good response. } \\
\text { Low toxicity. } \\
\text { Good performance status } \\
\text { retains. } \\
\text { Allows to stratify into risk } \\
\text { groups. } \\
\text { A role in prophylaxis. }\end{array}$ & $\begin{array}{l}\text { Applicable only in CD20+ PTLD. } \\
\text { Specific adverse effects (progress- } \\
\text { ing multifocal leukoencephalopathy); } \\
\text { hypogammaglobulinemia; Hepatitis B } \\
\text { reactivation. }\end{array}$ \\
\hline Antiviral drugs & $\mathrm{EBV}+$ & $\begin{array}{l}\text { Promising role if combined } \\
\text { with viral thymidine kinase } \\
\text { inducers (arginine butyrate). }\end{array}$ & $\begin{array}{l}\text { Non-effective as monotherapy } \\
\text { (thymidine kinase non-expressed in } \\
\text { EBV+ PTLD). } \\
\text { Only in EBV-positive cases. }\end{array}$ \\
\hline $\begin{array}{l}\text { Intravenous } \\
\text { immunoglobulin (IVIG) }\end{array}$ & $\mathrm{EBV}+$ & $\begin{array}{l}\text { Theoretical interest due to } \\
\text { precence of EBV-specific } \\
\text { antibodies. }\end{array}$ & $\begin{array}{l}\text { As a combination with other treatment } \\
\text { methods, absence of data on its real } \\
\text { efficiency. }\end{array}$ \\
\hline
\end{tabular}

Notes: GvHD, Graft Versus Host Disease; IVIG, intravenous immunoglobulins.

\section{Our clinical experience and discussion}

We have analyzed our experience in allogeneic HSCTs performed over 1994-2011 at the Bone Marrow Transplantation Department at the Republican Pediatric Hospital (RPH) and Institute of Children Hematology, as well as allo-HSCTs carried out within 2012-2016 at the Dmitry Rogachev National Scientific and Practical Center of Pediatric Hematology, Oncology and Immunology (Moscow, Russia). From 1994 to 2011,361 allo-HSCT were performed at the BMT Department, with 27 cases of EBV reactivation ( $8 \%$ of total). Among them, 9 patients showed EBV viremia followed by spontaneous resolution, whereas, in twelve cases, EBV loads required preventive therapy with Rituximab.

In six patients, EBV-associated lymphoproliferative syndrome was observed. Of those PTLD cases, three children received Rituximab treatment with clinical effect; two children required combined therapy with Rituximab and cytostatic chemotherapy. In one child, the disorder proceeded in a fulminant manner, showing no response to Rituximab. Among the group with documented EBV reactivation, eight children have been lost, including three cases of primary disease ( 1 case was combined with PTLD). In two patients, death was caused by chronic GvHD complicated by infections; in 1 case, lethal outcome was due to heart insufficiency in PTLD with clinical response to Rituximab. One lethal outcome occurred due to multiorgan failure underlied by EBV viremia, and only one case of EBV-associated PTLD proceeded in fulminant manner, with liver and abdominal lymph node affection, thus becoming an immediate cause of death. Clinical characteristics of all patients with EBV reactivation is presented in Table 4. The data on PTLD patients are shown in Table 5. 
Table 4. Clinical features of the patients with EBV reactivation

\begin{tabular}{|c|c|}
\hline Parameters & Number of patients \\
\hline Total amount & 27 \\
\hline $\begin{array}{l}\text { Gender: } \\
\text { Boys } \\
\text { Girls }\end{array}$ & $\begin{array}{l}17 \\
10\end{array}$ \\
\hline $\begin{array}{l}\text { Age: } \\
0-10 \text { years old } \\
\text { over } 10 \text { years old }\end{array}$ & $\begin{array}{l}18 \\
9\end{array}$ \\
\hline $\begin{array}{l}\text { Primary diagnosis: } \\
\text { Aplastic anemia } \\
\text { Acute myeloblastic leukemia } \\
\text { Acute biphenotypic leukemia } \\
\text { Myelodysplastic syndrome } \\
\text { Mucopolysaccharidosis type I } \\
\text { Primary immune deficiency } \\
\text { Juvenile myelomonocytic leukemia } \\
\text { Acute lymphoblastic leukemia } \\
\text { Hodgkin's disease } \\
\text { Fanconi anemia } \\
\text { X-linked adrenoleukodystrophia }\end{array}$ & $\begin{array}{l}4 \\
4 \\
4 \\
3 \\
3 \\
3 \\
2 \\
1 \\
1 \\
1 \\
1\end{array}$ \\
\hline $\begin{array}{l}\text { Donor type: } \\
\text { HLA matched related } \\
\text { HLA matched unrelated (5, one mismatch; } 1 \text {, with } 2 \text { mismatches) } \\
\text { Haploidentical }\end{array}$ & $\begin{array}{l}8 \\
18 \\
1\end{array}$ \\
\hline $\begin{array}{l}\text { Conditioning regimens: } \\
\text { Busulfan-containing, } \\
\text { Of them with Melphalan } \\
\text { Treosulfan-containing } \\
\text { Nonmyeloablative, Fludara-containing }\end{array}$ & $\begin{array}{l}17 \\
8 \\
5 \\
5\end{array}$ \\
\hline $\begin{array}{l}\text { GvHD prophylaxis: } \\
\text { Cyclosporine+Mycophenolate mofetil } \\
\text { Prograph+Mycophenolate mofetil } \\
\text { Cyclosporine+ Methotrexate } \\
\text { Corticosteroids }\end{array}$ & $\begin{array}{l}10 \\
15 \\
1 \\
1\end{array}$ \\
\hline Engraftment & 25 \\
\hline Acute GvHD, stage 2-4 & 16 \\
\hline $\begin{array}{l}\text { Chronic GvHD: } \\
\text { Total case number } \\
\text { Limited } \\
\text { Extensive }\end{array}$ & $\begin{array}{l}16 \\
4 \\
12\end{array}$ \\
\hline CMV reactivation & 13 \\
\hline EBV viremia, non-treated & 9 \\
\hline EBV viremia, Rituximab preventive therapy & 12 \\
\hline $\begin{array}{l}\text { EBV-PTLD: } \\
\text { Total case number } \\
\text { Rituximab treatment } \\
\text { Rituximab + chemotherapy treatment }\end{array}$ & $\begin{array}{l}6 \\
4 \\
2\end{array}$ \\
\hline $\begin{array}{l}\text { Mortality: } \\
\text { Total case number } \\
\text { Relapse } \\
\text { Chronic GvHD + infections } \\
\text { Heart insufficiency (EBV-PTLD in anamnesis) } \\
\text { Multiorgan failure } \\
\text { EBV-PTLD }\end{array}$ & $\begin{array}{l}8 \\
3 \\
2 \\
1 \\
1 \\
1\end{array}$ \\
\hline
\end{tabular}


Table 5. Characteristics of the EBV-PTLD patients

\begin{tabular}{|c|c|c|c|c|c|c|}
\hline Characteristics & Patient 1 & Patient 2 & Patient 3 & Patient 4 & Patient 5 & Patient 6 \\
\hline $\begin{array}{l}\text { Age at the time } \\
\text { of HSCT, years }\end{array}$ & 3 & 1,5 & 12 & 11 & 10 & 4 \\
\hline Gender & female & male & male & male & male & male \\
\hline Diagnosis & ALL & AML & AA & MDS, RAEB & AA & $\begin{array}{l}\text { Acute } \\
\text { biphenotypic } \\
\text { leukemia }\end{array}$ \\
\hline Donor type & MUD & MUD & $\begin{array}{l}\text { MUD (B-mis- } \\
\text { match) }\end{array}$ & MUD & $\begin{array}{l}\text { MRD } \\
\text { (repeated HSCT) }\end{array}$ & MUD \\
\hline $\begin{array}{l}\text { EBV status, } \\
\text { (serology in } \\
\text { patient/donor) }\end{array}$ & $+/+$ & $+/+$ & $+/+$ & $+/+$ & $+/+$ & $+/-$ \\
\hline $\begin{array}{l}\text { Conditioning } \\
\text { regimen }\end{array}$ & $\begin{array}{l}\text { Treosulfan, } \\
\text { Fludarabine- } \\
\text { Tiothepa, ATG }\end{array}$ & $\begin{array}{l}\text { Treosulfan, } \\
\text { Fludarabine, } \\
\text { Melphalan, } \\
\text { Thymoglobulin }\end{array}$ & $\begin{array}{l}\text { TA0, } \\
\text { Cyclophospha- } \\
\text { mide, } \\
\text { Fludarabine, } \\
\text { Thymoglobulin }\end{array}$ & $\begin{array}{l}\text { Busulfan, } \\
\text { Fludarabine, } \\
\text { Thymoglobulin }\end{array}$ & $\begin{array}{l}\text { TA0, } \\
\text { Cyclophospha- } \\
\text { mide, } \\
\text { Fludarabine, } \\
\text { Thymoglobulin }\end{array}$ & $\begin{array}{l}\text { Busulfan, } \\
\text { Fludarabine, } \\
\text { Melphalan, } \\
\text { Thymoglobulin }\end{array}$ \\
\hline $\begin{array}{l}\text { GvHD } \\
\text { prophylaxis }\end{array}$ & $\begin{array}{l}\text { Cyclosporin + } \\
\text { Methotrexate }\end{array}$ & $\begin{array}{l}\text { Tacrolimus, } \\
\text { Mycopheno- } \\
\text { late mofetil } \\
\end{array}$ & $\begin{array}{l}\text { Tacrolimus, } \\
\text { Mycopheno- } \\
\text { late mofetil }\end{array}$ & $\begin{array}{l}\text { Tacrolimus, } \\
\text { Mycopheno- } \\
\text { late mofetil }\end{array}$ & $\begin{array}{l}\text { Tacrolimus, } \\
\text { Mycopheno- } \\
\text { late mofetil }\end{array}$ & $\begin{array}{l}\text { Tacrolimus, } \\
\text { Mycopheno- } \\
\text { late mofetil } \\
\end{array}$ \\
\hline $\begin{array}{l}\text { Graft cellular- } \\
\text { ity, nucleated } \\
\text { cells (x10 } / \mathrm{kg} \text { ) }\end{array}$ & 6,5 & 9 & 5 & 6 & 4,6 & 7 \\
\hline $\begin{array}{l}\text { Engraftment, } \\
\text { days }\end{array}$ & 12 & 33 & 22 & No & 27 & 16 \\
\hline Acute GvHD & Grade 1 & 0 & Grade 1 & 0 & 0 & Grade 1 \\
\hline Chronic GvHD & 0 & 0 & $\begin{array}{l}\text { Skin and liver } \\
\text { lesions }\end{array}$ & 0 & 0 & 0 \\
\hline $\begin{array}{l}\text { CMV } \\
\text { reactivation }\end{array}$ & No & $\begin{array}{l}\text { Yes, CMV } \\
\text { pneumonia }\end{array}$ & Yes & Yes & No & Yes \\
\hline Graft problems & No & $\begin{array}{l}\text { Relapse at } 5 \\
\text { months }\end{array}$ & No & $\begin{array}{l}\text { Graft failure, } \\
\text { autoimmune } \\
\text { hemolysis, } \\
\text { Hypofunction } \\
\text { of } 2^{\text {nd }} \text { graft }\end{array}$ & Rejection & No \\
\hline Repeated HSCT & & & & $\begin{array}{l}\text { Repeated HSCT } \\
\text { with Alemtu- } \\
\text { zumab }\end{array}$ & Repeated HSCT & \\
\hline $\begin{array}{l}\text { Long-term } \\
\text { immuno- } \\
\text { suppressive } \\
\text { therapy (corti- } \\
\text { costeroiods >6 } \\
\text { months) } \\
\end{array}$ & No & No & Yes & Yes & No & No \\
\hline $\begin{array}{l}\text { Terms of PTLD } \\
\text { development, } \\
\text { months }\end{array}$ & $4 \mathrm{mo}$ & $3 \mathrm{mo}$ & $4 \mathrm{mo}$ & $\begin{array}{l}4 \text { months after } \\
\text { repeated HSCT }\end{array}$ & $\begin{array}{l}1 \text { month after } \\
\text { repeated HSCT }\end{array}$ & $2 \mathrm{mo}$ \\
\hline $\begin{array}{l}\text { Clinical } \\
\text { presentation }\end{array}$ & $\begin{array}{l}\text { EBV viremia } \\
\text { (high), } \\
\text { acute } \\
\text { hepatitis, } \\
\text { enlarged ab- } \\
\text { dominal lymph } \\
\text { nodes }\end{array}$ & $\begin{array}{l}\text { EBV viremia, } \\
\text { lymphade- } \\
\text { nopathy, } \\
\text { lymph node } \\
\text { conglomerate } \\
\text { in abdominal } \\
\text { cavity, EBV } \\
\text { encephalitis }\end{array}$ & $\begin{array}{l}\text { EBV viremia, } \\
\text { fever, lymph } \\
\text { node conglom- } \\
\text { erate in left } \\
\text { cervical area, } \\
\text { soft mass in } \\
\text { oropharyngeal } \\
\text { area }\end{array}$ & $\begin{array}{l}\text { Lymphade- } \\
\text { nopathy, } \\
\text { hepatospleno- } \\
\text { megaly }\end{array}$ & $\begin{array}{l}\text { Lymphop- } \\
\text { roliferation } \\
\text { (oropharynx, } \\
\text { cervical lymph } \\
\text { nodes) }\end{array}$ & $\begin{array}{l}\text { EBV viremia, } \\
\text { EBV-associat- } \\
\text { ed encephalitis }\end{array}$ \\
\hline
\end{tabular}




\begin{tabular}{|c|c|c|c|c|c|c|}
\hline Characteristics & Patient 1 & Patient 2 & Patient 3 & Patient 4 & Patient 5 & Patient 6 \\
\hline Diagnostics & EBV (PCR) & $\begin{array}{l}\text { EBV (PCR) } \\
\text { (blood) }\end{array}$ & $\begin{array}{l}\text { EBV (PCR) } \\
\text { (blood) } \\
\text { Lymph node } \\
\text { bioptate } \\
\text { histology, EBV } \\
\text { (PCR) in biop- } \\
\text { sy, immuno- } \\
\text { histochemical } \\
\text { (B cell markers } \\
\text { of PTLD) }\end{array}$ & $\begin{array}{l}\text { Rising lgG, } \\
\text { oligoclonality }\end{array}$ & $\begin{array}{l}\text { EBV (PCR) } \\
\text { (blood), Lymph } \\
\text { node bioptate } \\
\text { histology: } \\
\text { plasma cell } \\
\text { hyperplasia, } \\
\text { EBV (PCR) in } \\
\text { bioptate }\end{array}$ & $\begin{array}{l}\text { EBV (PCR) } \\
\text { (blood, } \\
\text { cerebrospinal } \\
\text { fluid) }\end{array}$ \\
\hline $\begin{array}{l}\text { First-line } \\
\text { treatment }\end{array}$ & Rituximab №2 & Rituximab №4 & $\begin{array}{l}\text { Immunosup- } \\
\text { ression } \\
\text { therapy } \\
\text { discontinued } \\
\text { Rituximab №4 }\end{array}$ & Rituximab №4 & $\begin{array}{l}\text { Immuno- } \\
\text { supression } \\
\text { therapy } \\
\text { discontinued } \\
\text { Rituximab №4 }\end{array}$ & Rituximab №4 \\
\hline $\begin{array}{l}\text { Second-line } \\
\text { treatment }\end{array}$ & No & $\begin{array}{l}\text { Donor lympho- } \\
\text { cyte infusions } \\
\text { №3 } \\
\text { IVIG }\end{array}$ & $\begin{array}{l}\text { CHOP } \\
\text { №2 } \\
\text { Donor lympho- } \\
\text { cyte infusion } \\
\text { №2 } \\
\text { EBV-specific } \\
\text { donor cells №5 }\end{array}$ & No & No & $\begin{array}{l}\text { Rituximab } \\
\text { intralumbar, } \\
\text { High-dose } \\
\text { Methotrexate }\end{array}$ \\
\hline $\begin{array}{l}\text { Response to } \\
\text { therapy }\end{array}$ & No & No & $\begin{array}{l}\text { Response to } \\
\text { adoptive cell } \\
\text { therapy }\end{array}$ & $\begin{array}{l}\text { To the }{ }^{\text {st line }} \\
\text { treatment }\end{array}$ & $\begin{array}{l}\text { To the }{ }^{\text {st line }} \\
\text { treatment }\end{array}$ & $\begin{array}{l}\text { To the } 2^{\text {nd }} \text { line } \\
\text { treatment }\end{array}$ \\
\hline Outcome & $\begin{array}{l}\text { Death } 3 \text { weeks } \\
\text { from mani- } \\
\text { festing EBV } \\
\text { viremia }\end{array}$ & $\begin{array}{l}\text { Relapse, death } \\
6 \text { months from } \\
\text { HSCT }\end{array}$ & Alive & $\begin{array}{l}\text { Death with } \\
\text { heart insuffi- } \\
\text { ciency }\end{array}$ & Alive & $\begin{array}{l}\text { Alive, } \\
\text { hemiparesis, } \\
\text { symptomatic } \\
\text { epilepsy }\end{array}$ \\
\hline
\end{tabular}

Below, we would like to report a detailed description of the most severe clinical case where all available therapeutic options were applied (Patient 3).

\section{Clinical case description}

A boy with immune thrombocytopenia diagnosed at 6 years, received corticosteroids without effect; intravenous immunoglobulins (IVIG) with minimal effect. At the age of 10 years, the disorder was complicated by anemia and leukopenia. At the RPH Department of General Hematology, the diagnosis was formulated as follows: acquired idiopathic aplastic anemia, a supersevere form. Due to absence of related compatible donor, immunosupressive therapy was performed with cyclosporine, ATG (2 rounds), without any clinical effect. Multiple transfusions were complicated by hemosiderosis.

At the age of 12 years, the child underwent allogeneic hematopoietic stem cell transplantation from a compatible unrelated donor (9/10 antigens, mismatch for a $B$ locus) with minor ABO incombatibility, and EBV VCA IgG positivity in both donor and recipient. Conditioning regimen consisted of thoraco-abdominal irradiation at a dose of $2 \mathrm{~Gy}$; Fludarabine, $150 \mathrm{mg} / \mathrm{m}^{2}$, Cyclophosphamide, $100 \mathrm{mg} / \mathrm{kg}$; Thymoglobulin, $10 \mathrm{mg} / \mathrm{kg}$ (total doses are shown). Graft characteristics: nucleated cells, $5 \times 10^{8} / \mathrm{kg} ; \mathrm{CD} 34+$ cells, $3.14 \times 10^{6} / \mathrm{kg}$. GvHD prophylaxis was performed with Tacrolimus and Mycophenolate mofetil.
Engraftment was registered at the day +22 . Early posttransplant period was complicated by febrile neutropenia. Donor chimerism was developed at 2 months; blood group was changed to donor RBCs. Stage 1/2 acute GvHD was registered as skin affection, thus requiring Prednisolone administration for 1 month. In parallel, cytomegalovirus in blood was detectable, having been treated by Gancyclovir. Three months after HSCT, the patient developed persistent fever without response to antibiotics, as well as enlargement of left cervical lymph nodes. EBV viremia (2000 copies/mL) was first registered 2 weeks after these manifestations. Enhanced antibiotic therapy was without effect, the patient's condition became worse, febrile state persisted, accompanied by weakness, asthenia, cachexia. Lymph nodes at the neck area were enlarged, forming a solid conglomerate up to $5 \mathrm{~cm}$ in diameter. Lymph node biopsies were performed, followed by their examination at different reference centers (RPH, Moscow; Bureau for Pathology\&Anatomy, St. Petersburg). EBV was detected there by means of PCR. Histological pattern corresponded to monomorphic (Moscow), or polymorphic PTLD (St. Petersburg).

In Fig. 2, the results obtained at the Pathology Laboratory in St. Petersburg (Chief, Dr. Yu. A. Krivolapov). A lymphoid tissue fragment exhibited a pattern of lost organ structure. The tissue consisted of diffuse lymphoid cell fields with detectable small and medium-sized lymphocytes, plasmoblasts 


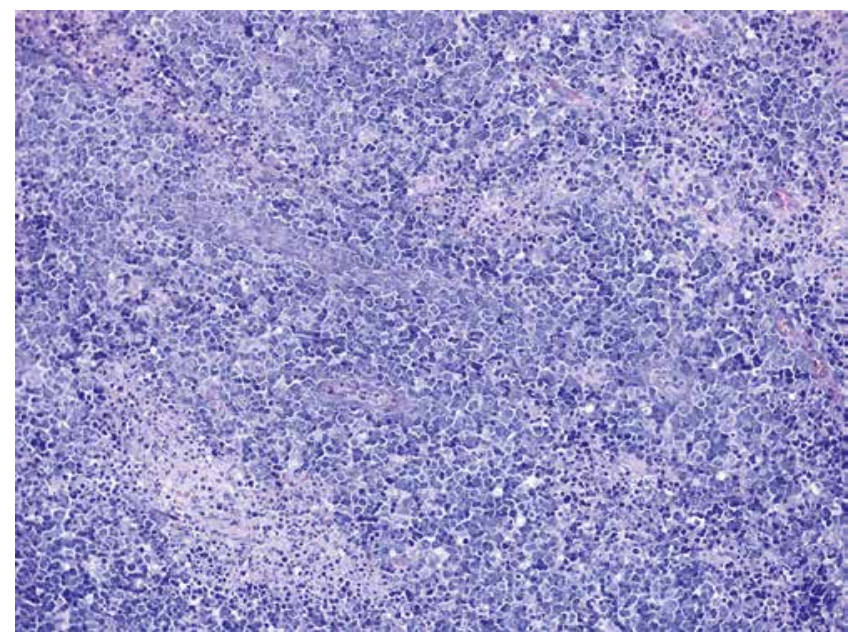

Figure 2. Lymphoid tissue fragment with the loss of topographical structure and polymorphic cell infiltration; hematoxylin and eosin stain, $\times 40$

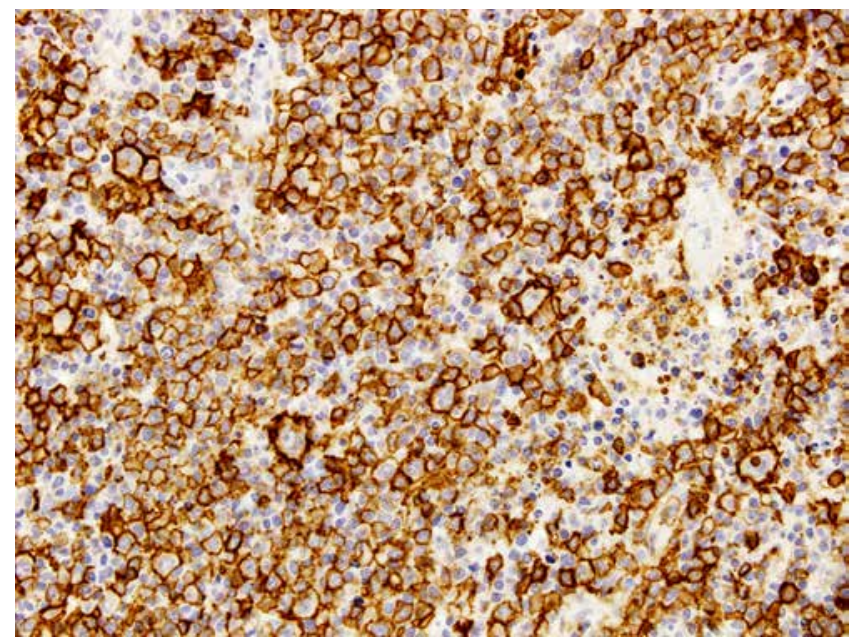

Figure 4. CD20 expression on the tumor cells. Immunohistochemical reaction; $\times \mathbf{4 0}$

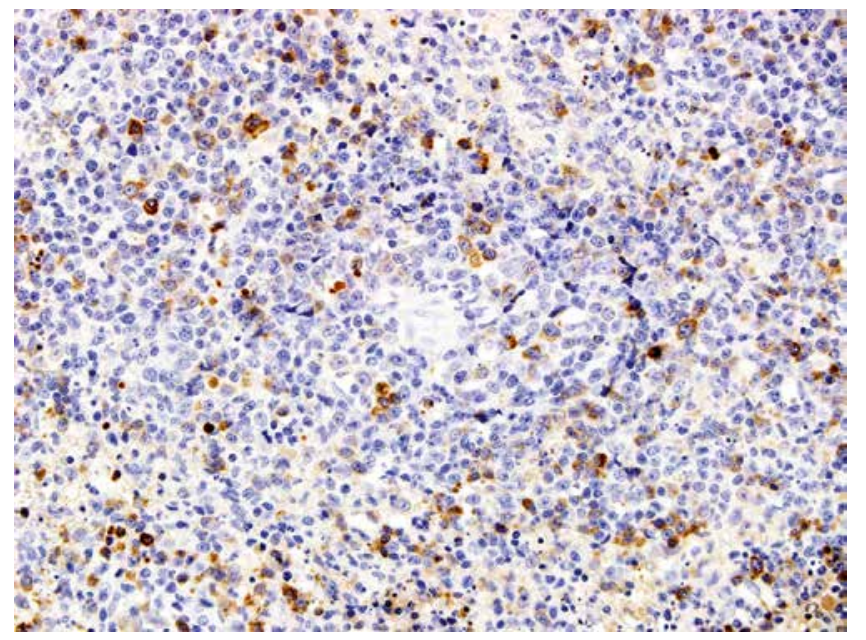

Figure 6. Kappa expression on the tumor cells. Immunohistochemical reaction; $\times 40$

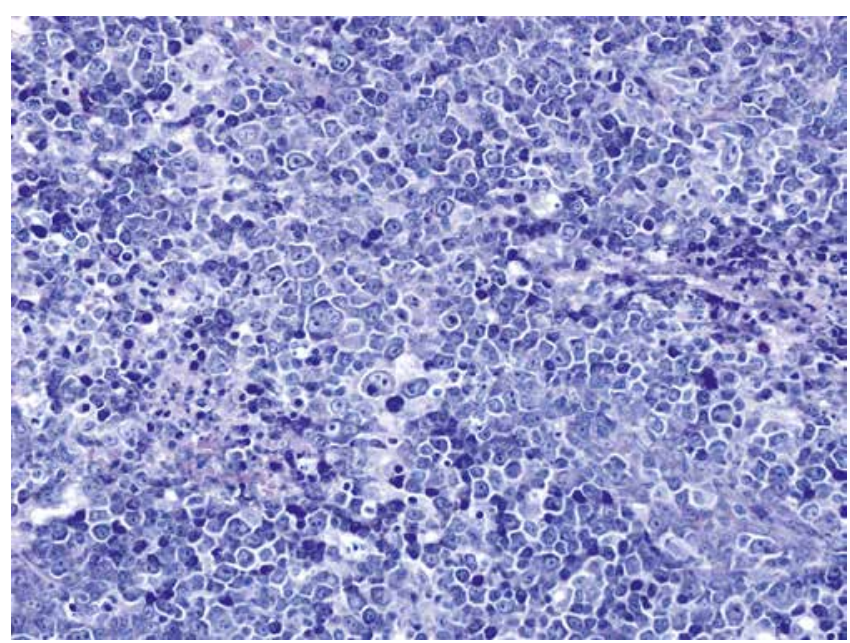

Figure 3. Polymorphic cell infiltrate; hematoxylin and eosin stain, $\times 40$

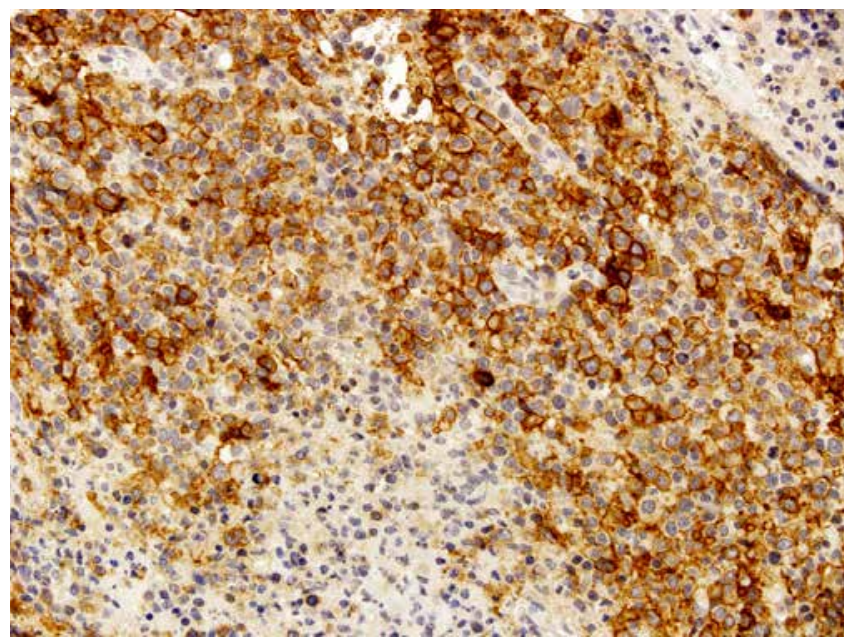

Figure 5. CD30 expression on the tumor cells. Immunohistochemical reaction; $\times 40$

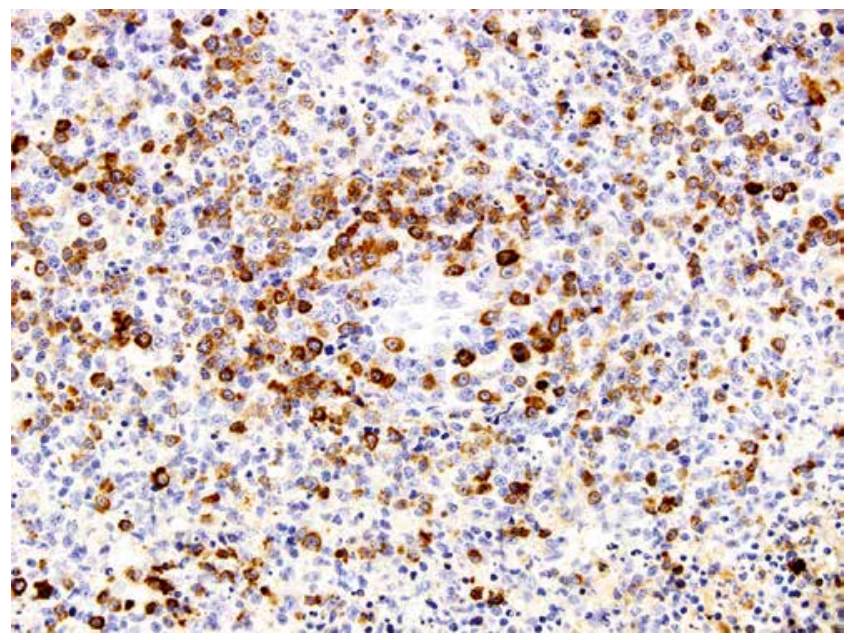

Figure 7. Lambda expression on the tumor cells. Immunohistochemical reaction; $\times 40$ 


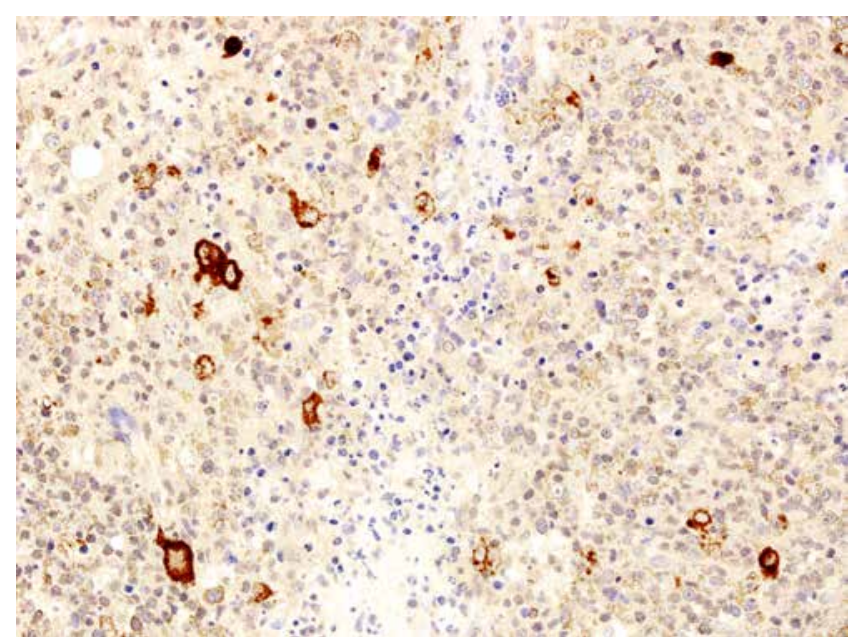

Figure 8. LMP1 expression on the tumor cells. Immunohistochemical reaction; $\times 40$

and immunoblasts, large atypical cells with giant, sometimes deformed nuclei with large homogenous nucleoli. Nearly all cells in the field have intensively basophilic cytoplasm (Fig. 3). Mitotic figures are observed. Numerous necrotic foci are revealed, with nuclear fragments (karyorrhexis). Upon immunohistochemical study, vast majority of proliferating cells expressed CD79a (JCB117) and MuM1(Mum1p), with lesser amounts of CD20 (L26)- positive lymphoid cells (Fig. 4). Activated lymphoid cells expressed CD30 (Ber-H2) (Fig. 5). Immunoglobulin light lambda chain-expressing lymphoid cells prevailed over kappa-positive cells in the samples of proliferating tissues (Fig. 6, 7). Large deformed immunoblasts are found there, being both kappa- and lambda-positive. Their cytoplasm showed intensive expression of latent EBV membrane LMP-1(CS1-4) protein (Fig. 8). A proliferative KiS5 antigen was expressed in nuclei of ca. 70\% of lymphoid cells. Few CD3+ T cells were seen (Fig. 9), with CD8(1A5) cells being prevalent over CD4(4B12)+ lymphocytes. The proliferating tissue did not contain detectable lymphoid cells expressing CALLA CD10 (56C6), or (ALK-1). Ziel-Nilsen Acid fast stain of slices with carbol fuchsin did not show acid-resistant bacteria. Staining with antibodies for M.bovis did not show this antigen. Clinical pattern of the disease, histological structure of lymphoid tissue under study, and immune histochemistry results correspond to polymorphic post-transplant lymphoproliferative disease.

Immunosuppression was discontinued as a first-line therapeutic measure, and treatment with Rituximab was started. Following 4 injections, clinical effect was not reached. Therefore, we undertook a second-line therapy which consisted of a single-block CHOP chemotherapy, which was complicated by enteroparesis. Within first days of chemotherapy, a decrease and softening of the lymph node conglomerate was registered, then followed by the tumor stabilization, with persisting febrile state.

We then started block A (Dexamethasone+Ifosfamide+ Methotrexate, $1 \mathrm{~g} / \mathrm{m}^{2}$ over $24 \mathrm{~h}+$ Cytosar + Vepeside, without Vincristine, due to recently observed neuropathy), accompanied by combined anti-infectious therapy. Despite treatment, the neck conglomerate was enlarged, along with

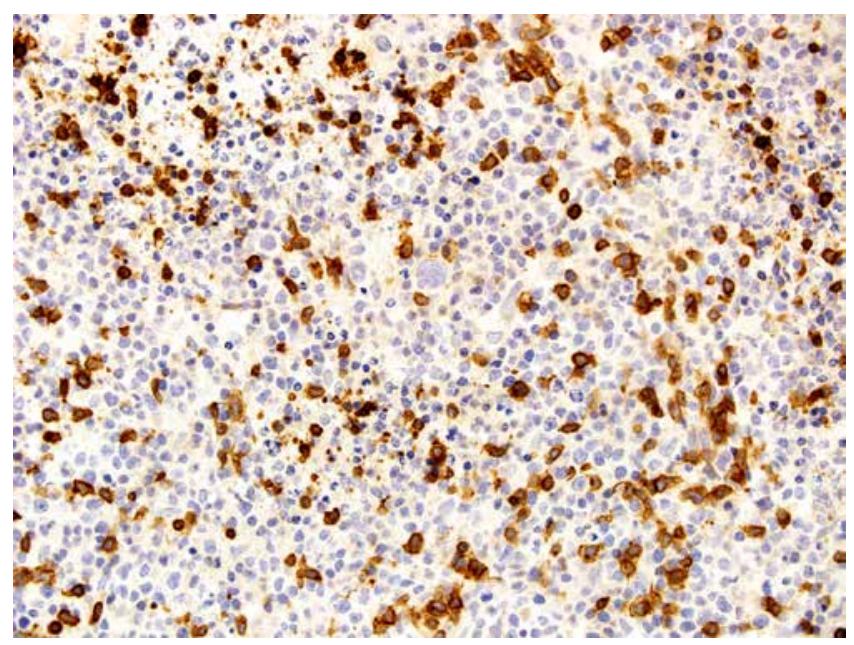

Figure 9. CD3 expression on the tumor cells. Immunohistochemical reaction; $\times 40$

continuous febrility. However, EBV was not more detectable in blood by means of PCR. Hence, this case of EBV-associated PTLD was considered refractory. A third block of polychemotherapy was scheduled, as follows: Gemsar, $1 \mathrm{~g} / \mathrm{m}^{2}$ (days 1-6); Carboplatine, $200 \mathrm{mg} / \mathrm{m}^{2}$ (days 2-5); Vepesid, $150 \mathrm{mg} / \mathrm{m}^{2}$ (days 2-5); Dexamethasone, $6 \mathrm{mg} / \mathrm{m}^{2}$ (days 1-6), followed by subsequent transfusion of donor hematopoietic cells (boost without conditioning): on day 3 after finishing therapy, the patient received CD34+ cells at a dose of $11 \times 10^{6}$ $\mathrm{kg}$, and CD3+ cells at a dose of $1 \times 10^{4} / \mathrm{kg}$. Two weeks later, the fever faded away, and hematopoiesis recovered. However, the boy showed signs of GvHD: dry skin, exfoliation, hyperpigmentation, weak itching. Nevertheless, a decision was taken to continue donor lymphocyte infusions (DLI). Three weeks after first lymphocyte infusion, a second DLI was performed (CD3+ cells, $\left.5 \times 10^{4} / \mathrm{kg}\right)$. Febrile state did resume, but the neck lymph node conglomerate was reduced in size, and hepatosplenomegaly retained. Liver enzyme markers became increased to $400 \mathrm{U} / \mathrm{L}$ (ALT and AST); alcaline phosphatase, to $1400 \mathrm{U} / \mathrm{L}$ ). Toxic hepatitis was diagnosed, and hepatotoxic drugs were withdrawn. However, the condition of patient became worse, i.e., loss of appetite and weight, enteric symptomes occurred, along with icterus and hepatosplenomegaly (liver $+8 \mathrm{~cm}$, spleen $+2 \mathrm{~cm}$ ). Blood biochemistry: total bilirubin of $84 \mathrm{mcmol} / \mathrm{L} ;$ ALT, $1060 \mathrm{U} / \mathrm{L}, \mathrm{AST}, 2217$ U/L, alcaline phosphatase, $2630 \mathrm{U} / \mathrm{L}$. Spot/papule eruptions developed at the the skin of head, trunk, as well as mucosal leukoplakia, and intestinal syndrome considered as grade 3 GvHD, with skin, mucosae, liver, intestinal tract lesions consequent to DLI. Corticosteroid treatment was resumed, at 2 $\mathrm{mg} / \mathrm{kg} /$ day. As result, eruptions were entirely reduced, like as fever, vomitimg and nausea. However, fatigue, low appetite, intestinal syndrome, signs of sinusitis, lung and intestinal infections (cytomegaloviral and adenoviral colitis). The patient received massive combined antibacterial and antiviral therapy (Cydofovir), antifungal treatment.

PTLD features were still detectable in MRI: heterogenous, thickened, soft, contrast-accumulating tissue retained in nasopharinx area, posterior nasal passages; posterior oropharynx (more at right side) looks deformed, mandibular lymph nodes were enlarged on the right. A heterogenous soft tis- 
sue mass persisted in lateral part of neck (left side, 18x9x31 $\mathrm{mm}$ in size), containing highly dense inclusions (microcalcinates), without proven contrast accumulation. Later on, a volumic decrease in lymphoproliferative changes was noted.

One month later, glucocorticoids were gradually tapered and fully discontinued. Rapamycin was administered as a basic immunosuppressive drug, aiming for immunotherapy, along with gamma-Interferon ( 2 injections). Clinical condition of the patient remained quite severe being characterized by cachexia, fever, adynamia, graft hypofunction with transfusion demands and requirements for hematopoiesis stimulation. Remarkable cholestasis was also documented (total bilirubin, $256 \mathrm{mcmol} / \mathrm{L}$ (direct,162); ALT, $147 \mathrm{U} / \mathrm{L}$; AST, $174 \mathrm{U} / \mathrm{L}$; alcaline phosphatase, $1224 \mathrm{U} / \mathrm{L}$; GGTP, $1372 \mathrm{U} / \mathrm{L})$, like as hemosiderosis (ferritin, $46545 \mathrm{mcg} / \mathrm{L}$ ).

From these data, we suggested a secondary hemophagocytic syndrome underlied by EBV infection in immunocompromised patient subjected to unrelated allo-HSCT. Dexamethasone therapy was started (10 mg/m² №12), Vepesid (150 $\mathrm{mg} / \mathrm{m}^{2}$ twice a week). Fever was stopped, and the size of liver and spleen was diminished. However, infectiuos complications still progressed, along with hypoalbuminemia and oedemas. Antibacterial and accessory treatment was further modified. E.g., grafting of CD34+ cells (10x10\% $\mathrm{kg}$ ) was performed, aiming for acceleration of hematopoiesis recovery. During the therapy, small positive changes were documented as decrease of febrile rises, reduced abdominal pains. IST was continued with Rapamycin, and substitutive IVIG transfusions at higher doses were performed, biphosphonates were also administered.

MRI of laryngo-pharyngeal area 8 months after starting PTLD therapy, showed that the right oropharinx, left nasal passages, and left cervical area retain soft tissue lesions; some features of lymphoproliferative lesions in maxillar sinus are also present. By the present, EBV viremia comprised 600 copies/mL, followed by increase to 4320 copies/mL. In parallel, CMV-viremia did also elevate. Therapy with EBV-specific lymphocytes from the same donor was scheduled.

During the waiting period, due to problems with breathing and swallowing, the mass in oropharynx was removed preceded by tracheostoma mounting. Clinical state remained very severe due to infectious complications underlied by pancytopenia and cholestasis syndromes. A month later, the tracheostome was removed. Therapy with EBV-specific donor cytotoxic lymphocytes was commenced (a total of five injections weekly). The therapy was associated with diminished lymph nodes, gradual improvement of blood counts, as well as slow decrease in liver toxicity markers, EBV viremia. Immune reconstitution seemed to proceed with time.

1.5 years after HSCT, there were no additional data for active PTLD (i.e., a year and 3 months after beginning the therapy), main problems concerned hepatic dysfunction and hepatosplenomegaly, along with liver fidrosis and hemochromatosis. The patient has received a long-term therapy with Budenofalk and Exjade.
Subsequently, gradual recovery of somatic status was observed, the boy underwent regular control examinations, replacement therapy with IVIG. His state stabilized 2 years after HSCT. There retaine hepatosplenomegaly, slight increase in hepatic transaminases and alcaline phosphatase. Budenofalk was continued for 3 years. Age-dependent vaccination was performed. At the present time, 10 years after allogeneic HSCT, clinical state of the adolescent is satisfactory, he is learning and keeps active life.

The above clinical description demonstrates an extremely aggressive course of some PTLD cases, thus requiring rapid and precise actions from the doctors. The pathological process developed within typical terms ( 3 months after HSCT), in absence of immune reconstitution, and exhibited and manifested as an infectious condition with fever and lymphadenopathy. Despite limited localization (oropharynx and cervical regions), the disorder proved to be refractory and threatened with asphyxia at certain stage of disease. Appropriate diagnostics required combined diagnostic measures with dominating histochemical results. Despite a divergent interpretation of mono- or polymorphic lesions in the given EBV-associated PTLD, clinical course and somatic status of the patient determined a vitla demand for changes and careful selection of adequate therapy. One should note professionalism of the medical team, as well as precise actions, patience and insistence of the doctor that determined favorable outcome of this case which initially presented a life-threatening situation.

Meanwhile, the first case presented in Table 5 concerns fulminant course of EBV-PTLD. A 3-year old girl with acute lymphoblastic leukemia (ALL) was subject to allo-HSCT from HLA-compatible, EBV-positive unrelated donor with partial CD34+ graft enrichment. EBV viremia in the patient was registered at 4 months posttransplant, reaching 12,000 copies/mL. A week later, the viremia was increased to 500,000 copies/mL, accompanied by fever; liver damage as documented by growth in transaminases, rising bilirubin; enlarged abdominal lymph nodes. After two Rituximab injections, no positive effect was reached, her condition deteriorated rapidly, and the patient died due to progressing hepatic and respiratory failure. Only three weeks passed since EBV viremia was registered in the girl. Two-week therapy with Rituximab proved to be without any effect. This type of EBV-PTLD (any histology data are not available, due to lacking autopsy) showed a quite aggressive and rapid course, thus preventing alternative therapeutic options. Other PTLD cases observed (see Table 5) depict more favorable variants of the disorder, with positive response to the IST reduction and Rituximab treatment. Interestingly, the patient No.6 developed EBV-associated PTLD despite EBV-seronegativity in his donor, may be, due to endogenous infection of donor cells from recipient. Another unusual presentation of PTLD was connected with affection of central nervous system. However, there was no opportunity to perform stereotactic brain biopsy at the time of encephalitis manifestation. Later on, a biopsy did not reveal an initial cellular substrate. However, a marked response to Rituximab, e.g., its endolumbar injections, and to Methotrexate therapy are indicative for malignant origin of primary CNS lesions in the given patient. 
A study of the second cohort of patients who received allo-HSCT from 2012 to 2016 at the NCPHOI has revealed only two EBV-PTLD cases among 911 children (Table 6). This cohort was analysed separately, because the transplants were performed mostly by a novel protocol with a CD19 depletion and inclusion of Rituximab into the conditioning regimen. Among 483 patients after HSCT with alpha/beta depletion and CD19-negative selection, as well as among 316 children who received Rituximab, no single case of PTLD was registered. However, B cell depletion was not performed in the two belowmentioned cases: the first patient was grafted with umbilical blood from unrelated donor. The second patient received bone marrow from a sibling. Therefore, their conditioning regimens were classic, with Thymoglobulin application which is considered an accessory risk factor for PTLD. Description, of these 2 cases, PTLD manifestations and their treatment are seen from Table 6.

Table 6. Characteristics of the two patients with monomorphic B cell PTLD

\begin{tabular}{|c|c|c|}
\hline Characteristics & Patient 1 & Patient 2 \\
\hline Age at the time of $\mathrm{HSCT}$, years & 8 & 14 \\
\hline Gender & Girl & Boy \\
\hline Diagnosis & Acute myeloblastic leukemia & Aplastic anemia \\
\hline Donor type & $\begin{array}{l}\text { MUD (umbilical blood compati- } \\
\text { ble for } 6 / 10 \text { antigens) }\end{array}$ & MRD \\
\hline $\begin{array}{l}\text { EBV state (serology) in patient/ } \\
\text { donor pairs }\end{array}$ & $+/-$ & $+/+$ \\
\hline Conditioning regimen & $\begin{array}{l}\text { Treosulfan, Fludarabine, } \\
\text { Melphalan, Thymoglobulin }\end{array}$ & Fludarabine, Cyclophosphamide, Thymoglobulin \\
\hline GvHD prophylaxis & Tacrolimus+corticosteroids & Cyclosporin+ Mycophenolate mofetil \\
\hline $\begin{array}{l}\text { Graft cellularity, nucleated } \\
\text { cells }\left(x 10^{8} / \mathrm{kg}\right)\end{array}$ & 6.5 & 3.54 \\
\hline Engraftment, days & 12 & 12 \\
\hline Acute GvHD & $\begin{array}{l}\text { Grade } 2 \text {, skin and intestinal } \\
\text { affection }\end{array}$ & 0 \\
\hline Chronic GvHD & $\begin{array}{l}\text { Intestinal immune lesion, } \\
\text { abdominal pains }\end{array}$ & 0 \\
\hline CMV reactivation & Yes & No \\
\hline Graft problems & Graft failure & No \\
\hline Repeated HSCT & $\begin{array}{l}\text { Mesenchymal stem cells from } \\
3^{\text {rd }} \text { party №5 }\end{array}$ & No \\
\hline $\begin{array}{l}\text { Prolonged immunosuppression } \\
\text { (corticosteroids > } 6 \text { months) }\end{array}$ & Yes & No \\
\hline Terms of PTLD development & 5 months & $\begin{array}{l}\text { Begun since } 2 \text { months, progression with culmination by } 4 \\
\text { months. }\end{array}$ \\
\hline Clinical presentation & $\begin{array}{l}\text { Lesions of tonsils, cervical } \\
\text { lymph nodes, liver, spleen, } \\
\text { intestines, lungs. } \\
\text { Febrile state. }\end{array}$ & $\begin{array}{l}\text { EBV viremia } 2 \text { months later, foci in liver and spleen, enlarged } \\
\text { intra-abdominal lymph nodes. } \\
\text { Ulcer of esophageal/cardiac junction. } \\
4 \text { months later, enlargement of submandibular lymph nodes, } \\
\text { left tonsil, bulky mass at the left parapharyngeal area. } \\
\text { Generalization of the process, relapsing course. }\end{array}$ \\
\hline Diagnostics & $\begin{array}{l}\text { EBV (PCR) in tonsillar tissue; } \\
\text { Histology of a removed tonsil: } \\
\text { monomorphic B cell PTLD } \\
\text { (DLCBCL NOS tygpe) }\end{array}$ & $\begin{array}{l}\text { EBV (PCR) in tonsillar tissue. } \\
\text { Histology (biopsy from submandibular lymph node): } \\
\text { EBV-associated PTLD } \\
\text { Biopsy of parapharyngeal mass: EBV+ diffuse large-cell } \\
\text { B cell lymphoma (monomorphic PTLD). } \\
\text { MRI, PET. }\end{array}$ \\
\hline
\end{tabular}




\begin{tabular}{|c|c|c|}
\hline Characteristics & Patient 1 & Patient 2 \\
\hline First-line treatment & Rituximab №4 & $\begin{array}{l}\text { Rituximab №4: preventive therapy, refractoryness } \\
\text { Cytosar, } 6 \mathrm{~g} / \mathrm{m}^{2} \mathrm{~N} N 3 \\
\text { Etoposide, } 125 \mathrm{mg} / \mathrm{m}^{2} \mathrm{~N} N 4 \\
\text { Intratecal injection of Cytosar, Methotrexate, } \\
\text { Dexamethasone, } \\
\text { Anti-CD20 (Gasyva) №1 }\end{array}$ \\
\hline Second-line treatment & $\begin{array}{l}\text { Actemra (anti-IL6 antibody) } \\
\text { IVIG } \\
\text { Rituximab №4 (2 }{ }^{\text {nd }} \text { course) }\end{array}$ & $\begin{array}{l}\text { Dexamethasone } \\
\text { Chemotherapy (CHOP) } \\
\text { Brentuximab Vedotin №1 } \\
\text { Nivolumab (anti-PDI) №5 } \\
\text { Actemra №1 } \\
\text { Radiation therapy, at a total dose of } 46 \text { Gy } \\
\text { DLI №1 (CD45RA-) }\end{array}$ \\
\hline Response & Partial & Yes \\
\hline Outcome & $\begin{array}{l}\text { Persistence of a compound dis- } \\
\text { order (chronic GvHD, EBV-PTLD, } \\
\text { poor performance state). }\end{array}$ & $\begin{array}{l}\text { Condition became stable over } 1 \text { year and } 2 \text { months after } \\
\text { HSCT, } 8 \text { months of the EBV-PTLD therapy. }\end{array}$ \\
\hline
\end{tabular}

These two cases also refer to aggressive and malignant clinical forms of PTLD. The first case concerned a girl with acute myeloblastic leukemia following allografting and development of refractory acute and chronic GvHD without any options of immunotherapy. The B cell monomorphic PTLD did partially respond to Rituximab treatment. More active treatment modes were impossible, due to poor somatic condition of thefemale patient.

In the boy with aplastic anemia, we have documented all stages of EBV-PTLD emergence, including progression from EBV viremia and lymphadenopathy to mucosal lesions (bleeding gastric ulceration requiring partial stomach resection, tonsillar involvement) followed by outgrowth of parapharyngeal tumor mass. We were also able to confirm histologically a transition from polymorphic PTLD to monomorphic aggressive form being similar to malignant large-cell lymphoma by
B cell origin (Fig. 10). Such clinical course is rarely described in details, both for clinical and histological pattern, hence this case seems to be original, due to concordance between evolution of modifying pathological pattern and specific treatment mode. At the stage of EBV-associated lymphoadenopathy, a standard approach with Rituximab therapy was applied, however, without effect. This monomorphic PTLD was refractory to therapy with anti-CD20 antibodies. At the next stage, the EBV-PTLD proceeded as a malignant B cell large-cell lymphoma (Fig. 11), this requiring a highdose chemotherapy. In future, standard polychemotherapy proved to be insuffisient, and clinical effect was obtained only from combined chemotherapy, immune drugs and donor lymphocyte infusion. Nivolumab and Brentuximab were used as a pioneering approach to treatment of such condition. In both children, antibodies against IL- 6 were also used with proven effect, in order to ameliorate clinical symptoms.

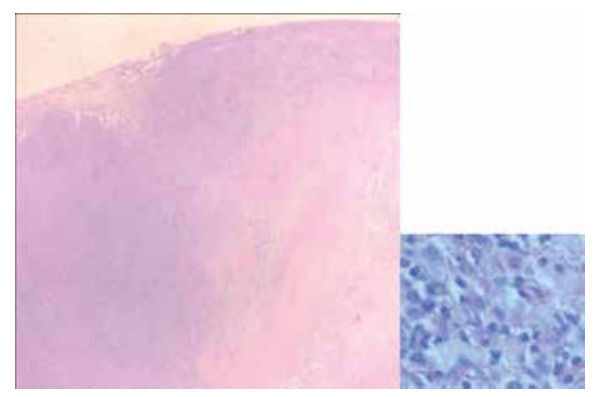

a)

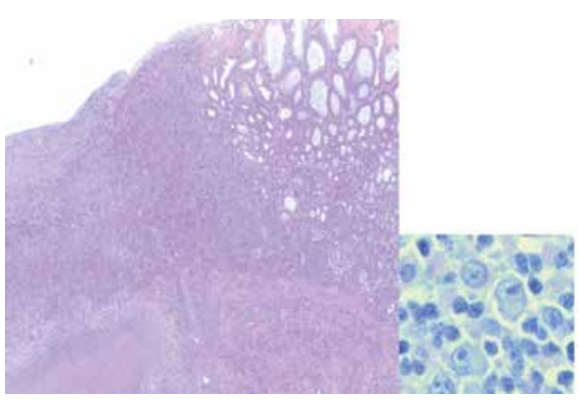

b)

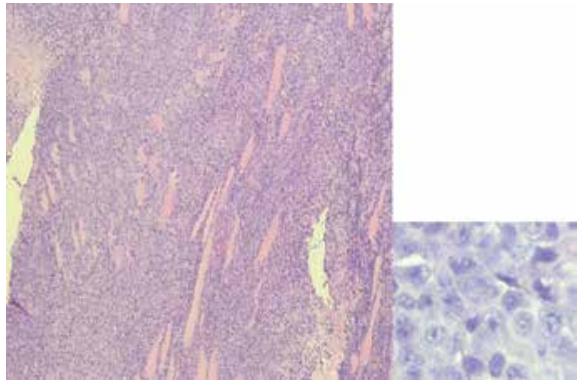

c)

Figure 10. Pathomorphosis of PTLD in one patient.

a. hematoxylin and eosin stain; $x 10, x 40$. Early PTLD lymph node lesion. The loss of topographic structure, focuses of necrosis, polymorphic cell infiltrate with large EBV-positive cells.

b. hematoxylin and eosin stain; x10, x40. Polymorhic PTLD, mucocutaneous ulcer of the antral stomach. The mucose of the antral stomach with ulceration and a massive transmural infiltration of lamina propria. Polymorphic cell infiltrate with numerous EBV-positive large cells, plasmacytic cells and plasmoblasts, small CD3/CD8 reactive T-lymphocytes.

c. hematoxylin and eosin stain; x20, x40. Monomorphic B-cell PTLD, diffuse large cell B-cell lymphoma. Monomorphic large cell infiltrate with the diffuse distribution among the muscled fibers. Cells with a high mytotic activity - immunoblasts and centroblasts. 

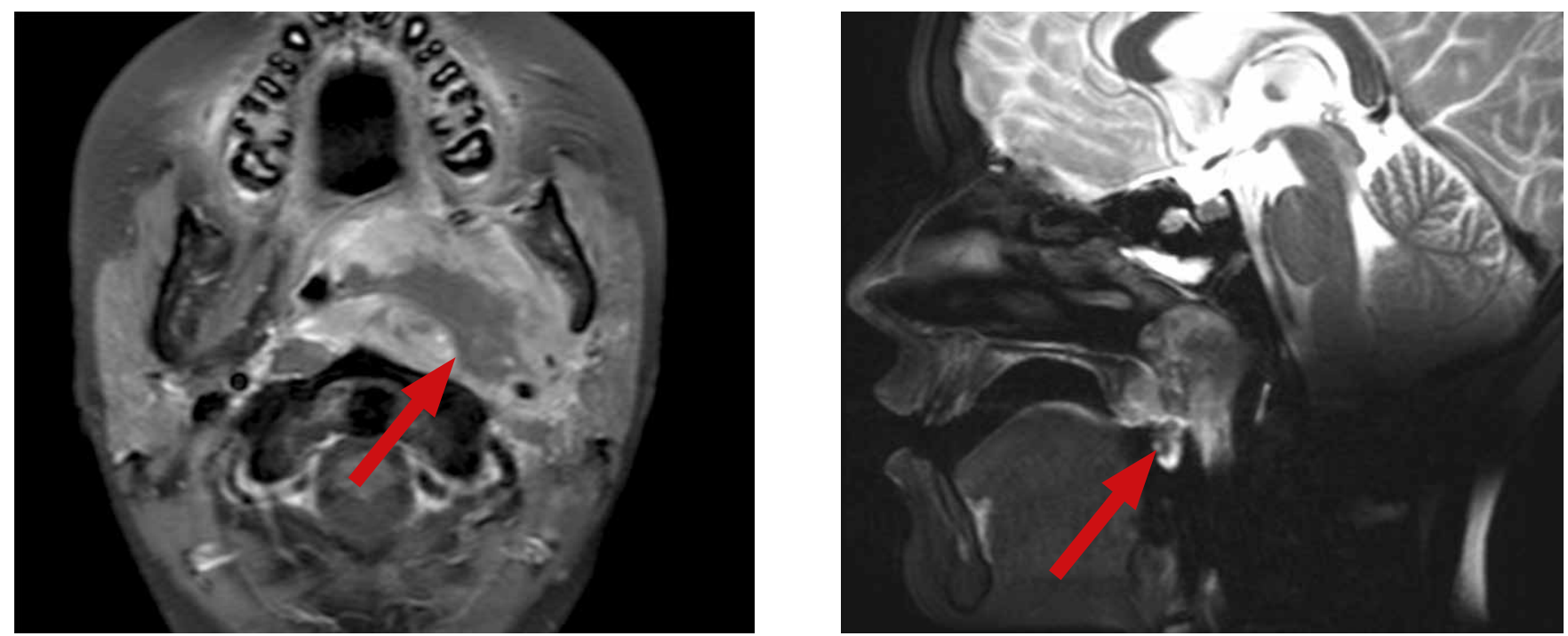

Figure 11. MRI in Tl-VI with contrast enchancement and fat supression in axial projection and T2-VI with fat supression in sagittal projection. Tumor mass of the lateropharyngeal space on the left with ingomogenius intensive contrast accumulation; left tonsilla invlovement, nasal pharynx and pharynx invasion.

\section{Conclusion}

Hence, PTLD is a challenging pathological process which lets a lot of open questions be answered by appropriate specialists. This complication still bears a risk of high mortality, thus requiring further activities for studying pathogenesis and treatment modes for PTLD. Multicenter research and clinical studies are necessary to evaluate this clinical entity. The PTLD therapy represents an excellent clinical model for combined application of immune therapy, cellular therapy, and standard cytostatic treatment of malignancies which may be used for treatment of other neoplasias and severe viral infections.

\section{Conflict of interest}

No conflict of interests is declared.

\section{References}

1. Andreone P, Gramenzi A, Lorenzini S, Biselli M, Cursaro C, Pileri S, Bernardi M. Posttransplantation lymphoproliferative disorders. Arch Intern Med. 2003;163(17):1997-2004.

2. Baker KS, DeFor TE, Burns LJ, Ramsay NK, Neglia JP, Robison LL. New malignancies after blood or marrow stemcell transplantation in children and adults: incidence and risk factors. J Clin Oncol. 2003 ; 21(7):1352-1358.

3. Blaes AH, Peterson BA, Bartlett N, Dunn DL, Morrison VA. Rituximab therapy is effective for posttransplant lymphoproliferative disorders after solid organ transplantation: results of a phase II trial. Cancer. 2005;104(8):1661-1667.

4. Bollard CM, Rooney CM, Heslop HE. T-cell therapy in the treatment of post-transplant lymphoproliferative disease. Nat Rev Clin Oncol. 2012 Sep;9(9):510-519.

5. Brunstein CG, Weisdorf DJ, DeFor T, Barker JN, Tolar J, van Burik JA, Wagner JE. Marked increased risk of Ep-
stein-Barr virus-related complications with the addition of antithymocyte globulin to a nonmyeloablative conditioning prior to unrelated umbilical cord blood transplantation. Blood. 2006;108(8):2874-2880.

6. Chen W, Huang Q, Zuppan CW, Rowsell EH, Cao JD, Weiss LM, Wang J. Complete absence of KSHV/HHV-8 in posttransplant lymphoproliferative disorders: an immunohistochemical and molecular study of 52 cases. Am J Clin Pathol. 2009;131(5):632-9.

7. Cockfield SM. Identifying the patient at risk for posttransplant lymphoproliferative disorder. Transpl Infect Dis. 2001 ; 3(2):70-78. Review.

8. Cohen J.I. Epstein-Barr virus lymphoproliferative disease associated with acquired immunodeficiency. Medicine (Baltimore), 1991;70:137-160.

9. Cohen JM, Cooper N, Chakrabarti S, Thomson K, Samarasinghe S, Cubitt D, Lloyd C, Woolfrey A, Veys P, Amrolia PJ. EBV-related disease following haematopoietic stem cell transplantation with reduced intensity conditioning. Leuk Lymphoma. 2007;48(2):256-269.

10. Comoli P, Labirio M, Basso S, Baldanti F, Grossi P, Furione $M$, Viganò $M$, Fiocchi R, Rossi G, Ginevri F, Gridelli B, Moretta A, Montagna D, Locatelli F, Gerna G, Maccario R. Infusion of autologous Epstein-Barr virus (EBV)-specific cytotoxic T cells for prevention of EBV-related lymphoproliferative disorder in solid organ transplant recipients with evidence of active virus replication. Blood. 2002 ; 99(7):25922598.

11. Dierickx D, Tousseyn T, Gheysens O. How I treat posttransplant lymphoproliferative disorders. Blood. 2015;126(20):2274-2283.

12. Dierickx D, Tousseyn T, Sagaert X, Fieuws S, Wlodarska I, Morscio J, Brepoels L, Kuypers D, Vanhaecke J, Nevens F, Verleden G, Van Damme-Lombaerts R, Renard M, Pirenne J, De Wolf-Peeters C, Verhoef G. Single-center analysis of 
biopsy-confirmed posttransplant lymphoproliferative disorder: incidence, clinicopathological characteristics and prognostic factors. Leuk Lymphoma. 2013;54(11):2433-2440.

13. Doubrovina E, Oflaz-Sozmen B, Prockop SE, Kernan NA, Abramson S, Teruya-Feldstein J, Hedvat C, Chou JF, Heller G, Barker JN, Boulad F, Castro-Malaspina H, George D, Jakubowski A, Koehne G, Papadopoulos EB, Scaradavou A, Small TN, Khalaf R, Young JW, O’Reilly RJ. Adoptive immunotherapy with unselected or EBV-specific T cells for biopsy-proven EBV+ lymphomas after allogeneic hematopoietic cell transplantation. Blood. 2012;119(11):2644-2656.

14. Durandy A. Anti-B cell and anti-cytokine therapy for the treatment of post-transplant lymphoproliferative disorder: past, present, and future. Transpl Infect Dis. 2001;3(2):104107.

15. Elstrom RL, Andreadis C, Aqui NA, Ahya VN, Bloom RD, Brozena SC, Olthoff KM, Schuster SJ, Nasta SD, Stadtmauer EA, Tsai DE. Treatment of PTLD with rituximab or chemotherapy. Am J Transplant. 2006;6(3):569-576.

16. Epstein-Barr virus and lymphoproliferative disorders after transplantation. [No authors listed] Am J Transplant. 2004; 4 (Suppl 10):59-65.

17. Frizzera G, Hanto DW, Gajl-Peczalska KJ, Rosai J, McKenna RW, Sibley RK, Holahan KP, Lindquist LL. Polymorphic diffuse B-cell hyperplasias and lymphomas in renal transplant recipients. Cancer Res. 1981;41(11, Pt 1):42624279.

18. Gong JZ, Bayerl MG, Sandhaus LM, Sebastian S, Rehder CW, Routbort M, Lagoo AS, Szabolcs P, Chiu J, Comito M, Buckley PJ. Posttransplant lymphoproliferative disorder after umbilical cord blood transplantation in children. Am J Surg Pathol. 2006; 30(3): 328-336.

19. Gottschalk S, Rooney CM, Heslop HE. Post-transplant lymphoproliferative disorders. Annu Rev Med. 2005; 56:2944.

20. Grulich AE, van Leeuwen MT, Falster MO, Vajdic CM. Incidence of cancers in people with HIV/AIDS compared with immunosuppressed transplant recipients: a meta-analysis. Lancet. 2007;370(9581):59-67.

21. Gustafsson A, Levitsky V, Zou JZ, Frisan T, Dalianis T, Ljungman P, Ringden O, Winiarski J, Ernberg I, Masucci MG. Epstein-Barr virus (EBV) load in bone marrow transplant recipients at risk to develop posttransplant lymphoproliferative disease: prophylactic infusion of EBV-specific cytotoxic T cells. Blood. 2000;95(3):807-814.

22. Haddad E, Paczesny S, Leblond V, Seigneurin JM, Stern M, Achkar A, Bauwens M, Delwail V, Debray D, Duvoux C, Hubert P, Hurault de Ligny B, Wijdenes J, Durandy A, Fischer A. Treatment of B-lymphoproliferative disorder with a monoclonal anti-interleukin- 6 antibody in 12 patients: a multicenter phase 1-2 clinical trial. Blood. 2001;97(6):15901597.

23. Haque T, Wilkie GM, Taylor C, Amlot PL, Murad P, Iley A, Dombagoda D, Britton KM, Swerdlow AJ, Craw- ford DH., et al. Treatment of Epstein-Barr-virus-positive post-transplantation lymphoproliferative disease with partly HLA-matched allogeneic cytotoxic T cells. Lancet. 2002 ;360(9331):436-442.

24. Harris NL, Ferry JA, Swerdlow SH. Posttransplant lymphoproliferative disorders: summary of Society for Hematopathology Workshop. Semin Diagn Pathol. 1997;14(1):8-14.

25. Hoover R.N. Lymphoma risks in populations with altered immunity - a search for mechanism. Cancer Res 1992; 52: $5477 \mathrm{~s}$.

26. Jaffe ES, Harris NL, Stein H, et al. Pathology and genetics of tumours of the haematopoietic and lymphoid tissues. In: World Health Organization Classification of Tumours, vol.3, Lyon, France: IARC Press, 2001:264-269.

27. Knowles DM, Cesarman E, Chadburn A. Correlative morphologic and molecular genetic analysis demonstrates three distinct categories of posttransplantation lymphoproliferative disorders. Blood. 1995 ;85(2) :552-565.

28. Krishnamurthy S, Hassan A, Frater JL, Paessler ME, Kreisel FH. Pathologic and clinical features of Hodgkin lymphoma-like posttransplant lymphoproliferative disease. Int J Surg Pathol. 2010; 18(4): 278-285.

29. Leblond V, Davi F, Charlotte F, Dorent R, Bitker MO, Sutton L, Gandjbakhch I, Binet JL, Raphael M. Posttransplant lymphoproliferative disorders not associated with Epstein-Barr virus: a distinct entity? J Clin Oncol. 1998;16(6):2052-2059.

30. Liebowitz D. Epstein-Barr virus and a cellular signaling pathway in lymphomas from immunosuppressed patients. $\mathrm{N}$ Engl J Med 1998; 338: 1413-1421.

31. Lin JC, Smith MC, Pagano JS. Prolonged inhibitory effect of 9-(1,3-dihydroxy-2-propoxymethyl)guanine against replication of Epstein-Barr virus. J Virol. 1984; 50(1): 50-55.

32. Loren AW, Porter DL, Stadtmauer EA, Tsai DE. Post-transplant lymphoproliferative disorder: a review. Bone Marrow Transplant. 2003;31(3):145-155.

33. Lowe T., S.Bhatia, G.Somlo. Second malignancies after allogeneic hematopoietic cell transplantation. Biol Blood Marrow Transplant. 2007; 13:1121-1134.

34. Luskin MR, Heil DS, Tan KS, Choi S, Stadtmauer EA, Schuster SJ, Porter DL, Vonderheide RH, Bagg A, Heitjan DF, Tsai DE, Reshef R. The impact of EBV status on characteristics and outcomes of posttransplantation lymphoproliferative disorder. Am J Transplant. 2015;15(10):2665-2673.

35. Mathur A, Kamat DM, Filipovich AH, Steinbuch M, Shapiro RS. Immunoregulatory abnormalities in patients with Epstein-Barr virus-associated B cell lymphoproliferative disorders. Transplantation. 1994; 57(7):1042-1045.

36. Morscio J, Dierickx D, Ferreiro JF, Herreman A, Van Loo P, Bittoun E, Verhoef G, Matthys P, Cools J, Wlodarska I, De Wolf-Peeters C, Sagaert X, Tousseyn T. Gene expression profiling reveals clear differences between EBV-positive and EBV-negative posttransplant lymphoproliferative disorders. Am J Transplant. 2013;13(5):1305-1316. 
37. Morscio J, Tousseyn T. Recent insights in the pathogenesis of post-transplantation lymphoproliferative disorders. World J Transplant. 2016; 6(3):505-516.

38. Nalesnik M.A., L. Makowka, T.E. Starzl. The diagnosis and treatment of posttransplant lymphoproliferative disorders. Curr Probl Surg, 1988; 25: 367-472.

39. Nalesnik MA, Jaffe R, Starzl TE, Demetris AJ, Porter K, Burnham JA, Makowka L, Ho M, Locker J. The pathology of posttransplant lymphoproliferative disorders occurring in the setting of cyclosporine A-prednisone immunosuppression. Am J Pathol. 1988;133(1):173-192.

40. Nelson BP, Nalesnik MA, Bahler DW, Locker J, Fung JJ, Swerdlow SH. Epstein-Barr virus-negative post-transplant lymphoproliferative disorders: a distinct entity? Am J Surg Pathol. 2000;24(3):375-385.

41. Oertel SH, Verschuuren E, Reinke P, Zeidler K, PappVáry M, Babel N, Trappe RU, Jonas S, Hummel M, Anagnostopoulos I, Dörken B, Riess HB. Effect of anti-CD 20 antibody rituximab in patients with post-transplant lymphoproliferative disorder (PTLD). Am J Transplant. 2005;5(12):29012906.

42. Orazi A, Hromas RA, Neiman RS, Greiner TC, Lee CH, Rubin L, Haskins S, Heerema NA, Gharpure V, Abonour R, Srour EF, Cornetta K. Posttransplantation lymphoproliferative disorders in bone marrow transplant recipients are aggressive diseases with a high incidence of adverse histologic and immunobiologic features. Am J Clin Pathol. 1997; 107:419-429.

43. Orazi A, Hromas RA, Neiman RS, Greiner TC, Lee CH, Rubin L, Haskins S, Heerema NA, Gharpure V, Abonour R, Srour EF, Cornetta K. Systemic inflammatory response syndrome after administration of unmodified T lymphocytes. Mol Ther. 2014 ;22(6):1134-1138.

44. Patriarca F, Medeot M, Isola M, Battista ML, Sperotto A, Pipan C, Toffoletti E, Dozzo M, Michelutti A, Gregoraci G, Geromin A, Cerno M, Savignano C, Rinaldi C, Barbone F, Fanin R. Prognostic factors and outcome of Epstein-Barr virus DNAemia in high-risk recipients of allogeneic stem cell transplantation treated with preemptive rituximab. Transpl Infect Dis. 2013;15(3):259-267.

45. Penn I, Hammond W, Brettschneider L, Starzl TE. Malignant lymphomas in transplantation patients.Transplant Proc. 1969; 1:106-112.

46. Pitman SD, Huang Q, Zuppan CW, Rowsell EH, Cao JD, Berdeja JG, Weiss LM, Wang J. Hodgkin lymphoma-like posttransplant lymphoproliferative disorder (HL-like PTLD) simulates monomorphic B-cell PTLD both clinically and pathologically. Am J Surg Pathol. 2006 ;30(4):470-476.

47. Qu L, Xu S, Rowe D, Triulzi D. Efficacy of Epstein-Barr virus removal by leukoreduction of red blood cells. Transfusion. 2005;45(4):591-595.

48. Rohr JC, Wagner HJ, Lauten M, Wacker HH, Jüttner E, Hanke C, Pohl M, Niemeyer CM. Differentiation of EBV-induced post-transplant Hodgkin lymphoma from Hodg- kin-like post-transplant lymphoproliferative disease. Pediatr Transplant. 2008;12(4):426-431.

49. Rooney CM, Smith CA, Ng CY, Loftin SK, Sixbey JW, Gan Y, Srivastava DK, Bowman LC, Krance RA, Brenner MK, Heslop HE. Infusion of cytotoxic T cells for the prevention and treatment of Epstein-Barr virus-induced lymphoma in allogeneic transplant recipients. Blood. 1998; 92(5):15491555.

50. Rowlings PA, Curtis RE, Passweg JR, Deeg HJ, Socié G, Travis LB, Kingma DW, Jaffe ES, Sobocinski KA, Horowitz MM. Increased incidence of Hodgkin's disease after allogeneic bone marrow transplantation. J Clin Oncol. 1999;17(10):3122-3127.

51. Shapiro RS, McClain K, Frizzera G, Gajl-Peczalska KJ, Kersey JH, Blazar BR, Arthur DC, Patton DF, Greenberg JS, Burke B, et al. Epstein-Barr virus associated B cell lymphoproliferative disorders following bone marrow transplantation. Blood. 1988;71(5):1234-1243.

52. Snyder MJ, Stenzel TT, Buckley PJ, Lagoo AS, Rizzieri DA, Gasparetto C, Vredenburgh JJ, Chao NJ, Gong JZ. Posttransplant lymphoproliferative disorder following nonmyeloablative allogeneic stem cell transplantation. Am J Surg Pathol. 2004;28(6):794-800.

53. Socié G, Curtis RE, Deeg HJ, Sobocinski KA, Filipovich AH, Travis LB, Sullivan KM, Rowlings PA, Kingma DW, Banks PM, Travis WD, Witherspoon RP, Sanders J, Jaffe ES, Horowitz MM. New malignant diseases after allogeneic marrow transplantation for childhood acute leukemia. J Clin Oncol. 2000;18(2):348-357.

54. Starzl TE, Nalesnik MA, Porter KA, Ho M, Iwatsuki S, Griffith BP, Rosenthal JT, Hakala TR, Shaw BW Jr, Hardesty $\mathrm{RL}$, et al. Reversibility of lymphomas and lymphoproliferative lesions developing under cyclosporin-steroid therapy. Lancet. 1984; 1(8377):583-587.

55. Styczynski J, Reusser P, Einsele H, de la Camara R, Cordonnier C, Ward KN, Ljungman P, Engelhard D. Management of HSV, VZV and EBV infections in patients with hematological malignancies and after SCT: guidelines from the Second European Conference on Infections in Leukemia. Bone Marrow Transplant. 2009;43(10):757-770.

56. Takehana CS, Twist CJ, Mosci C, Quon A, Mittra E, Iagaru A. (18)F-FDG PET/CT in the management of patients with post-transplant lymphoproliferative disorder. Nucl Med Commun. 2014;35(3):276-281.

57. Trappe R, Oertel S, Leblond V, Mollee P, Sender M, Reinke P, Neuhaus R, Lehmkuhl H, Horst HA, Salles G, Morschhauser F, Jaccard A, Lamy T, Leithäuser M, Zimmermann H, Anagnostopoulos I, Raphael M, Riess H, Choquet S; German PTLD Study Group; European PTLD Network. Sequential treatment with rituximab followed by CHOP chemotherapy in adult B-cell post-transplant lymphoproliferative disorder (PTLD): the prospective international multicentre phase 2 PTLD-1 trial. Lancet Oncol. 2012;13(2):196206. 
58. Tsao L, Hsi ED. The clinicopathologic spectrum of posttransplantation lymphoproliferative disorders. Arch Pathol Lab Med. 2007;131(8):1209-1218.

59. Uhlin M, Wikell H, Sundin M, Blennow O, Maeurer M, Ringden O, Winiarski J, Ljungman P, Remberger M, Mattsson J. Risk factors for Epstein-Barr virus-related post-transplant lymphoproliferative disease after allogeneic hematopoietic stem cell transplantation. Haematologica. 2014;99(2):346352.

60. Wagner HJ, Cheng YC, Huls MH, Gee AP, Kuehnle I, Krance RA, Brenner MK, Rooney CM, Heslop HE. Prompt versus preemptive intervention for EBV lymphoproliferative disease. Blood. 2004;103(10):3979-3981.
61. Weinstock DM, Ambrossi GG, Brennan C, Kiehn TE, Jakubowski A. Preemptive diagnosis and treatment of Epstein-Barr virus-associated post transplant lymphoproliferative disorder after hematopoietic stem cell transplant: an approach in development. Bone Marrow Transplant. 2006;37(6):539-546.

62. Zallio F, Primon V, Tamiazzo S, Pini M, Baraldi A, Corsetti MT, Gotta F, Bertassello C, Salvi F, Rocchetti A, Levis A. Epstein-Barr virus reactivation in allogeneic stem cell transplantation is highly related to cytomegalovirus reactivation. Clin Transplant. 2013;27(4):E491-497.

\section{Посттрансплантационное лимфопролиферативное заболевание у детей после аллогенной транспланта- ции гемопоэтических стволовых клеток: опыт центра и обзор литературы}

Юлия В. Скворцова ${ }^{1}$, Дмитрий Н. Балашов ${ }^{1}$, Лариса Н. Шелихова ${ }^{1}$, Елена В. Скоробогатова ${ }^{2}$, Юрий А. Криволапов ${ }^{3}$, Ирина П. Шипицына ${ }^{1}$, Елена И. Гутовская ${ }^{1}$, Дина Д. Байдильдина ${ }^{1}$, Ирина И. Калинина $^{1}$, Ульяна Н. Петрова $^{1}$, Андрей Б. Абросимов ${ }^{1}$, Светлана Н. Козловская ${ }^{1}$, Михаил А. Масчан ${ }^{1}$, Дмитрий М. Коновалов ${ }^{1}$, Дмитрий С. Абрамов ${ }^{1}$, Галина В. Терещенко ${ }^{1}$, Александр Г. Румянцев ${ }^{1}$, Елена В. Самочатова ${ }^{1}$, Галина А. Новичкова ${ }^{1}$, Алексей А. Масчан ${ }^{1}$

${ }^{1}$ ФГБУ ННПЦ ДГОИ им. Дм. Рогачева МЗ РФ

2 ФГБУ РДКБ МЗ РФ

${ }^{3}$ ГУЗ «Ленинградское областное патологоанатомическое бюро»

Д-р Скворцова Юлия Валериевна, к.м.н., ст. науч. сотрудник, врач-гематолог, зам. зав. отделением ТГСК№2 ННПЦ ДГОИ им. Дм. Рогачева

Рабочий адрес: ФГБУ ННПЦ ДГОИ им. Дм. Рогачева

МЗ РФ, 117198, Москва, ул. Саморы Машела, д. 1
Контактный телефон: +7 (915) 0693743

Адрес электронной почты: yuscvo@mail.ru

\section{Резюме}

Среди различных осложнений аллогенной трансплантации гемопоэтических стволовых клеток (ТГСК) одним из самых тяжелых является посттрансплантационное лимфопролиферативное заболевание (ПТЛПЗ), проявляющееся неконтролируемой пролиферацией лимфоидной ткани. Пусковым механизмом, как правило, служит первичная инфекция, вызванная Эпштейн-Барр вирусом, или реактивация вируса в иммунокомпрометированном организме. В зависимости от вида ПТЛПЗ и динамики его развития данная патология может быть фатальной для пациента. В данной статье описаны: клинико-морфологическая классификация, факторы риска, клинические особенности, диагностика и лечение ПТЛПЗ, а также приведен клинический опыт диагностики и лечения данного осложнения на базе отделений ТГСК РДКБ и ННПЦ ДГОИ.

\section{Ключевые слова}

Аллогенная трансплантация гемопоэтических стволовых клеток, посттрансплантационное лимфопролиферативное заболевание. 